Article

\title{
Exploring the Use of a Spatio-Temporal City Dashboard to Study Criminal Incidence: A Case Study for the Mexican State of Aguascalientes
}

\author{
Rodrigo Tapia-McClung (1) \\ Centro de Investigación en Ciencias de Información Geoespacial, Contoy 137, Col. Lomas de Padierna, \\ Tlalpan CDMX 14240, Mexico; rtapia@centrogeo.edu.mx
}

Received: 24 January 2020; Accepted: 6 March 2020; Published: 12 March 2020

\begin{abstract}
By considering public safety as a relevant component of a smart city framework, the development and use of city dashboards that explore the spatio-temporal monitoring of crime incidence to help local governments base their decision-making process on evidence is becoming more relevant. This research deals with the case study of the state of Aguascalientes, Mexico, whose capital hosts the annual San Marcos Fair, considered the most important fair in the country. By developing an online dynamic platform consisting of several different modules that rely on the use of geovisual analytics for dynamic and interactive data display and exploration, authorities can gain insights about the times and locations of the impact of criminal incidence, detect patterns over space and time, and look into what actions could be put in place. This becomes useful in advancing a circular model of the smart city in which urban processes are observed, data is collected and analyzed, management and decision actions occur, and more data is collected to measure their effectiveness. By comparing statistics for the three year period of 2016-2018, it is found that the second year of the study had a significant decrease in pedestrian crime incidence during the Fair, supporting the use of city dashboards with geovisual analytics to help monitor urban processes and aid authorities in making decisions. Further research is needed to uncover more efficient practices to achieve inter-institutional collaboration and data sharing schemes that adhere to and boost the principles of the smart city.
\end{abstract}

Keywords: smart governance; geovisual analytics; city dashboards; smart cities; crime analysis

\section{Introduction}

One of the first published references of the term 'smart city' is by Gibson et al. in the early 1990s [1]. Nowadays, this concept embodies several possible meanings, depending on the topic of interest, the scope of the application, and the specific focus authors want to give [2-4]. Nonetheless, all are strongly related to urban life, planning, development, participation, and management. As a consequence, they are likely to receive different names like wired, virtual, ubiquitous, intelligent, information, digital, knowledge, learning, sustainable, green, and electric city $[3,5]$.

By presenting a review of different dimensions several authors have identified as prominent in the smart city frameworks, Allam et al. note the lack of a unique definition for smart city but identify, nonetheless, the existence of "overlapping and non-overlapping themes" [6]. Overall, it is of particular interest to note that only few authors explicitly identify public safety as a key dimension or domain of a smart city framework. Neirotti et al. propose a public security domain whose main objectives are to "help public organizations to protect citizens' integrity and their goods" [7]. Washburn et al. postulate public safety as one of the seven critical infrastructure components of a smart city, together with city administration, education, healthcare, real estate, transportation, and utilities [8]. Dirks et al. identify that public safety, as an element of the citizen system "can be made 'smarter' with the help of 
instrumentation, interconnection and intelligence" [9]. Nam et al. consider crime-free environments as part of the human dimension and human factors of a smart city [10].

In turn, Kitchin et al. put forward the idea of monitoring the city with indicators, benchmarking and (dynamic) dashboards that "enable one to know the city as it actually is through objective, trustworthy, factual data that can be statistically analysed and visualized to reveal patterns and trends and to assess how it is performing" [11]. Digital dashboards were introduced in the early 1990s [12] and there have been several efforts in the last thirty years to incorporate them into smart city frameworks in order to measure a city's performance [11] or pulse [5]. Colding et al. advocate that Information and Communication Technologies (ICT) of the smart city "have the potential to shape people's behavior in desirable ways that information campaigns and policy interventions cannot, and can help people make choices that are better for them and for society in large" [13]. At the same time, they stress the point that while ICT may be part of the solution, they also contribute to the "wicked problems of smart cities".

The use of dashboards in urban settings and governmental agencies has gained relevance as it lets decision-makers get a quick glimpse at what is going on in certain topics of interest with little effort $[14,15]$. It also allows them to get an overall idea of the state of a particular system of interest at a certain given time. While being very common to feed these dashboards with data coming from many different sources of potentially very different origins, properties, and qualities, it is important to ensure it makes sense to the final users. Examples of these dashboards can be found in bike-sharing and scooter companies [16], water and electricity consumption [17], revenue from parking meters or parking lot availability [18], and overviews of the current state of a city [19].

These types of data are usually becoming available at very rapid rates, aiming at providing the user with real-time updates of the current state of whatever is being measured. While usually analyzed and used for commercial purposes and the generation of more income (how is the demand and offer of bikes or scooters around the city, does a certain region require an increase on parking tolls due to high demand), there are other sources and purposes that can help local governments adopt digital technologies and aim them at improving different services they have to provide to the population, such as security and public safety.

Lock et al. [20] present a review of urban dashboards and point out that, in general, they are not used as a two-way communication approach with society. It is interesting to note that the existence of dashboards to monitor crime incidence are not found in the text or the references therein. It is clear that governments can profit from having the performance of many of their systems monitored and tuned, and public safety should not be left out. One possible downfall for public safety dashboards is that crime incidence data may not be available as rapidly as other types of data. However, police departments typically have GPS-equipped police cars and radios, so it is possible to plot the locations of these assets on a map. On the other hand, plotting real-time criminal incidents is far more complicated and delicate, in view of the due legal process and chain of custody protection, and the fact that the whole process of identifying responsible individuals, investigating, and generating conclusions takes time. This may be one of the reasons there appear to be few public dashboards available that deal with public safety and crime incidence issues that are "up-to-date" and rather show data from a few weeks or months back.

According to Few's definition of a dashboard, it is a "visual display of the most important information needed to achieve one or more objectives; consolidated and arranged on a single screen so the information can be monitored at a glance" [14]. While the idea was coined focusing on how this could be used for business and money-making, it was well received and permeated to other disciplines. While many dashboards have stemmed from the interest of businesses to quickly and efficiently provide answers to questions that could represent them either losing or making more money, there is a line of work on Business Intelligence that aims at precisely this: analyze myriads of data to help provide answers an help find new markets, predict demand of services in a certain region or time, and empower organizations by providing insights onto what might be a good data-based decision. 
Visual analytics [21] easily finds a niche while being incorporated into dashboards because it aims "to detect the expected and discover the unexpected". When dealing with data that has an inherent spatial component, such as criminal incidence, incorporating geovisual analytics [22,23] becomes of paramount importance. Furthermore, the fact that crime exhibits a well-known temporal nature [24,25], makes it even more relevant to incorporate geovisual analytics [26].

For instance, the City of London provides several different dashboards [27] built using Tableau, as does the City of Seattle [28]. On the other hand, the City of Toronto Police Department provides dashboards created using Microsoft Power BI [29] and ArcGIS [30]. Additional examples of crime analysis dashboards built using ESRI's ArcGIS tools exist for the cities of Brasilia, Brazil, Vancouver, Canada, Douglas County, USA, Halifax, Canada and Belize [31-35].

It is interesting to note that while some of these dashboards do in fact incorporate the spatial dimension of crime, some others only focus on creating reports and charts that give an overall glimpse of how crime is increasing or decreasing. In some, the user can specify the period of time to analyze, create charts from, and make comparisons between periods, but do not seem to allow further visualizations that delve deeper into gaining more insights about the spatio-temporal behavior of criminal incidence. Additionally, all these examples use proprietary or licensed software.

Two aspects become clearly relevant. First, not every police department or local government has the necessary economic resources to pay for commercial software licenses in order to develop dashboards in them. Second, space-time visualizations seem to not have enough attention. For this, an open-source perspective that brings together both space and time in a dynamic visualization, echoing the geovisual analytics approach, is desired.

GeoVISTA CrimeViz was also consulted, but was unavailable (page returns a 404 error). Its use was also discouraged when the software description indicated it uses the Google Maps API for Adobe Flash, as the latter is now considered to be an outdated technology. An example of an open-source initiative is the Pittsburgh Crime Map 2017, written in R and served as a Shiny app [36]. It shows similar functionality to that of the maps aforementioned but lacks the option to explore the time dimension and its source code is not available.

While R and Shiny are great options to start developing visualizations and interactive dashboards, a disadvantage of serving them from public domains is made evident when dealing with sensitive data such as crime reports. It may also be overly convoluted to install the different required components to serve Shiny apps from their own servers. Another disadvantage of serving apps from public domains is that they are usually limited by either bandwidth, storage, active hours per month, transactions, etc. It seems that in some cases, police departments feel safer with physically having control over storage and servers. Erring on the safe side, it may well be advantageous to first keep sensitive data on premises and start with an initial simple local development.

The pertinence of bringing the spatial and time dimensions together is to make available the benefits these techniques provide to local government officials who may be in charge of making decisions about patrolling routes, posting guards at conflictive locations or other resolutions that may improve the security of the citizenry. The combination of space and time becomes relevant once it is acknowledged that it is important to study and learn from trends and detect potential seasonal patterns.

It is in this sense that this research aims at exploring the use of a digital platform that helps visualize and analyze criminal incidence data collected by local authorities during several years. This is done by means of different modules that, by using officially provided databases, dynamically and interactively explore the spatio-temporal behavior of crime incidence in the State of Aguascalientes, Mexico. As soon as new data become available, changes can be reflected promptly and an up-to-date representation of what is happening in the territory can be delivered through the platform, provided data are in consistent formats, and are compatible with the database definition (as pointed out by Batty [37]). The City of Aguascalientes, the capital, hosts the annual "San Marcos Fair", considered to be the largest one in the country, attracting many visitors both from within and outside the state, making it an easy target for crime incidence to increase. The government of Aguascalientes was keen to 
get a better understanding on the dynamics of the crime incidence throughout the year and, of course, during the Fair. One goal of studying the spatio-temporal behavior of crime in the State and City of Aguascalientes is for the local government to be able to detect time frames and probable locations where they need to be attentive and careful for every upcoming edition of the Fair while, at the same time, keep monitoring other regions and incidences. The proposed prototype is framed in the use of science and technology to attend societal needs. Under these circumstances, the proposed approach deemed reasonable to first provide the State of Aguascalientes Ministry of Public Safety with an online dynamic map that would allow them to explore the spatio-temporal behavior of crime in the state and, in particular, in the city. It was later proven necessary to develop other tools to: (1) explore the spatial distribution of different crime types along different time scales; (2) compare density maps for three different sources of crime incidence in the state; (3) compare the average criminal incidence levels of the state to the national ones; (4) visually analyze the efficiency of police sectors; (5) visually analyze the historical probability by day of the week and time of day of events occurring on a certain surveillance camera and simulate a real-time event on the map that could be followed with some cameras; and (6) explore the possibility of following a particular event (e.g., carjacking) with the surveillance camera set up by locating the nearest cameras.

The sustaining arguments that led to the development of the proposed solution, together with the reasoning of why the spatio-temporal approach is relevant are presented, as are technical details of the proposed platform, along with a brief description of different stages of user-oriented design that the solution went through, the approach that was taken, and pitfalls that were encountered. This paper reports the results from using data from the General Attorney from 2016 to 2018. The ongoing project started in 2016 and showed its usefulness for the 2017 edition of the Fair, after the analysis of criminal incidence for 2016 helped detect locations of high concentration of criminal incidence during the Fair, and recommendations were made to the State Ministry of Public Safety. However, personnel from the Ministry were not available to comment on the specific locations and actions that took place during the 2017 edition. For 2018, unfortunately, results were not as good as 2017, as it was an overall bad year for the whole country. Nonetheless, the value of working together with the local authorities in order to put forward a prototype to help visualize and analyze spatio-temporal criminal data, detect patterns of crime incidence for a particular event in the city, evaluate the performance of local police authorities, and pose questions about the difficulty of adopting such systems in the Mexican setting is brought up. In order to ensure the continuity of authorities using the proposed approach, complete data sets for 2019 and subsequent years should be made available and curated in order to guarantee they meet the requirements and is compatible and comparable with the rest of the years.

\section{Materials and Methods}

\subsection{Study Area}

The State of Aguascalientes is located in the central-northern region of the country, about $480 \mathrm{~km}$ northwest of Mexico City, the capital of the country. A very small state, it covers an approximate area of $5470 \mathrm{~km}^{2}$ (about $0.03 \%$ of the country) and is subdivided into 11 municipalities. The central municipality, and capital of the state, also called Aguascalientes, contains about $76 \%$ of the population and accounts for around the \% of the criminal incidence in the state. The City of Aguascalientes has hosted the annual San Marcos Fair since 1828, which now attracts around 8 million visitors, on average, during the three-week period that the Fair lasts during April and May [38]. The Fair is considered to be the most important one in the country and includes different types of events such as concerts of both international and national artists, bullfighting events, charrería, and the largest livestock exhibition in Latin America [39].

Because of the high number of incoming visitors during the Fair, it is of special importance for the Ministry of Public Safety to have a better understanding of the dynamics of criminal incidence throughout this period. Figure 1 shows the location of the State of Aguascalientes. 


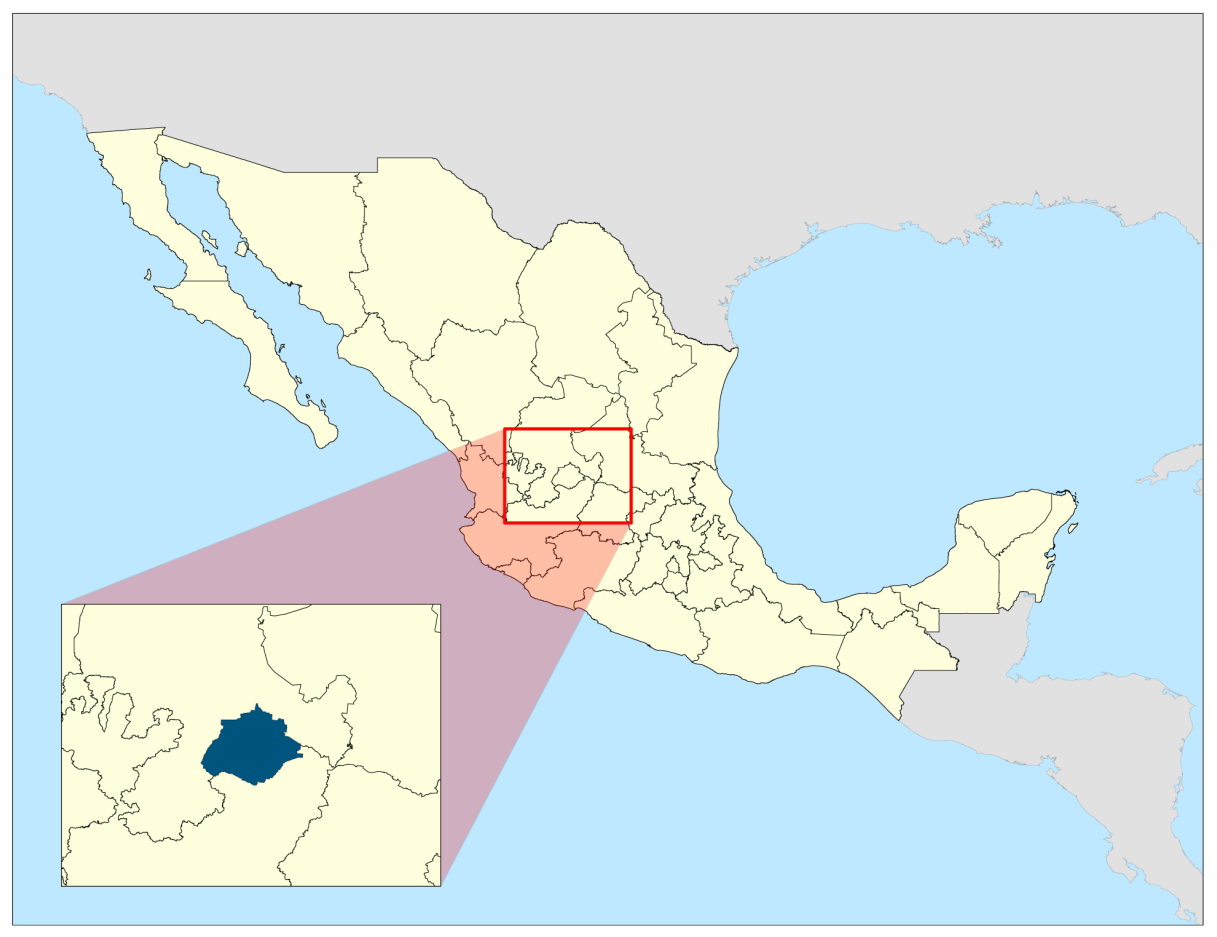

Figure 1. Location of the State of Aguascalientes, Mexico.

\subsection{Data}

Crime incidence data from official sources were made available to use throughout this study. It is important to note these are not open data sets, but rather provided for this study. The state of Aguascalientes C4 (Center for Command, Control, Communications, and Computing) was the institution in charge of mediating the interaction between the research team and the users, and they provided all data sets to be analyzed. The first leg of the project comprised using geo-referenced crime data records from the State's Attorney General's office from January 2011 to June 2016. Additional updates contained semester data for 2016, 2017, and 2018. A first critique to how data was made available, is that it would be desirable to manage monthly or even weekly updates to the database. However, as will be explained later on, this project brings together data sources from different entities which are not made available at the same time, thus making it even more difficult to have timely updates. Firstly, data from the Attorney General were made available as data tables of crime incidences that contained, among other fields, their spatial location and time of occurrence. Table 1 shows the number of available data points for each year.

Table 1. Number of yearly georeferenced criminal incidence reports for the state of Aguascalientes.

\begin{tabular}{lcccccccc}
\hline Year & $\mathbf{2 0 1 1}$ & $\mathbf{2 0 1 2}$ & $\mathbf{2 0 1 3}$ & $\mathbf{2 0 1 4}$ & $\mathbf{2 0 1 5}$ & $\mathbf{2 0 1 6}$ & $\mathbf{2 0 1 7}$ & $\mathbf{2 0 1 8}$ \\
\hline Data points & 10,667 & 11,529 & 10,168 & 9438 & 10,088 & 10,332 & 15,188 & 15,518 \\
\hline
\end{tabular}

The first data sets that were provided were suitable for the Attorney General's internal use, but not necessarily for other applications and uses. An initial data exploration of the first update showed inconsistencies with date formats for different periods, as records would have dates fields coded in one of many formats: YYYY/MM/DD, YYYY-MM-DD, YYYY/DD/MM, YYYY-DD-MM, etc. This made it difficult to completely automate the process of importing and updating data. C4 personnel who provided these data sets, and acted as intermediaries with other dependencies, were notified about this issue when it was first encountered with the expectation to ensure data providers would agree on a consistent date format and provide standardized data. This, however, did not occur and the date 
column for every update had to be manually checked and adjusted as a result, so new records would be compatible and comparable with previous ones. Additional data exploration yielded about 380 different crime types that were not classified using official catalogs [40,41]. Instead, local terminology that closely resembles the crime's modus operandi was used. This made it difficult to to discern in which category to properly place a given crime. To overcome this, a lookup table was created to translate the provided crime type to its official equivalent. After reclassifying crime data using this lookup table, the far more manageable size of 10 different categories was obtained.

Additional data sets from the Ministry of Public Safety and C4 records were later incorporated. These were cleaner and better formatted and were easier to use, but where only provided for 2017. However, it is important to note that each instance collects and stores crime incidence data for their own intents and purposes, so it certainly was an additional challenge to make them compatible. In the end, crime incidence from the Attorney General (2011-2018), 911 call records from C4 (2017), and incidence from the State's Public Ministry of Public Safety (2017) data sets were used. It is worth mentioning that the overall usefulness of these data sets was hampered since not all data sets were made available for the same periods of time. The impact of this situation is seen and explained in more detail later on in the proposed approach subsection.

The federal government, through the Executive Secretariat of the National Public Security System (Secretariado Ejecutivo del Sistema Nacional de Seguridad Pública, SESNSP) publishes monthly tabular data at the state and municipal level with how many incidents of each crime type occurred each month. In 2015, the Secretariat decided to update the methodology used to register and classify crimes for statistical purposes [42]. As a result, two different data sets are published: one for 2011-2017 with the old methodology [43] and another from 2015 onward with the new one [44]. The main difference between the old and new methodologies is that the new one contains some types of crime at a more disaggregated level. Dealing with observed values in tabular data, it is not possible to detect duplicate values from one methodology to the other. Since there are three years (2015-2017) with data from both the old and new methodologies, in order to obtain a full data set from 2011 to 2018 data from 2011-2014 from the old methodology together with that from 2015 onward were used. With this data preparation, a complete data set for 2011-2018 can be used to match the time frame made available by the Attorney General and show a general trend of how the state of Aguascalientes is doing in comparison to the rest of the country on a monthly basis. Additional cartographic data for the state of Aguascalientes (e.g., roads) were obtained from the National Institute of Statistics and Geography (Instituto Nacional de Estadística y Geografía (INEGI)) [45].

Apart from the date formatting issues mentioned above, failure to adhere to the use of official catalogs for classifying crime types and instead use local terminology, far from being a local or state issue, is recognized as a broader problem that encompasses many police agencies in many states and municipalities: a standard classification of crime is not used across all of them. Although there is an official catalog of crime types defined in 2011 and updated in 2018 [40,41], it is far from being adopted by local agencies and their personnel. More than just being an institutional disorder, it is a reflection of the existence of different state and federal penal codes.

It is important to note, as was mentioned before, that after the initial exploration of crime data sets, users were immediately notified about the inconsistencies their data showed. Specifically, date formats and crime types. An effort was made to make users and operators be aware of such issues and the impacts and consequences their carelessness would have on the project. Unfortunately, it did not seem to leave a mark on them, as every updated data set had similar problems. Overall, a huge attitude problem was detected in terms of different agencies sharing data for a common purpose. Ultimately, there was a sense that they did not feel very comfortable exchanging data and complying with suggestions from an external party. 


\subsection{The Relevance of Spatio-Temporal Analysis}

Once crime types from $\mathrm{C} 4$ data sets were successfully reclassified, it was possible to show some basic statistics. Table 2 shows the list of general crime types along with the percentage of occurrence for each one during 2016 and over all years.

Table 2. Percentage of occurrence for crime types in 2016 and all years for the state of Aguascalientes. Data from C4 and the Attorney General criminal incidence data set.

\begin{tabular}{lcc}
\hline Type of Crime & Percentage in 2016 & Percentage in 2011-2018 \\
\hline Carrier theft & $0.08 \%$ & $0.07 \%$ \\
Individual transport theft & $0.59 \%$ & $0.49 \%$ \\
Public transport theft & $0.32 \%$ & $0.75 \%$ \\
Recovered objects & $0.85 \%$ & $0.87 \%$ \\
Other thefts & $9.82 \%$ & $9.51 \%$ \\
\hline Auto parts theft & $13.39 \%$ & $14.11 \%$ \\
Business theft & $13.82 \%$ & $14.88 \%$ \\
Pedestrian theft & $13.30 \%$ & $15.22 \%$ \\
Vehicle theft & $24.74 \%$ & $18.23 \%$ \\
Household theft & $23.09 \%$ & $25.42 \%$ \\
\hline
\end{tabular}

From this table it can be seen that auto parts, business, pedestrian, vehicle, and household are the most common type of criminal incidents reported. The following analysis considers only these crimes. Once the temporal nature of the data is taken into account, the overall behavior of different crime types can be seen throughout the state. Figure 2 shows there is an increase in pedestrian and household crimes, while business and auto parts incidences seem to have very little variation, and vehicle theft has a declining tendency during the Fair.

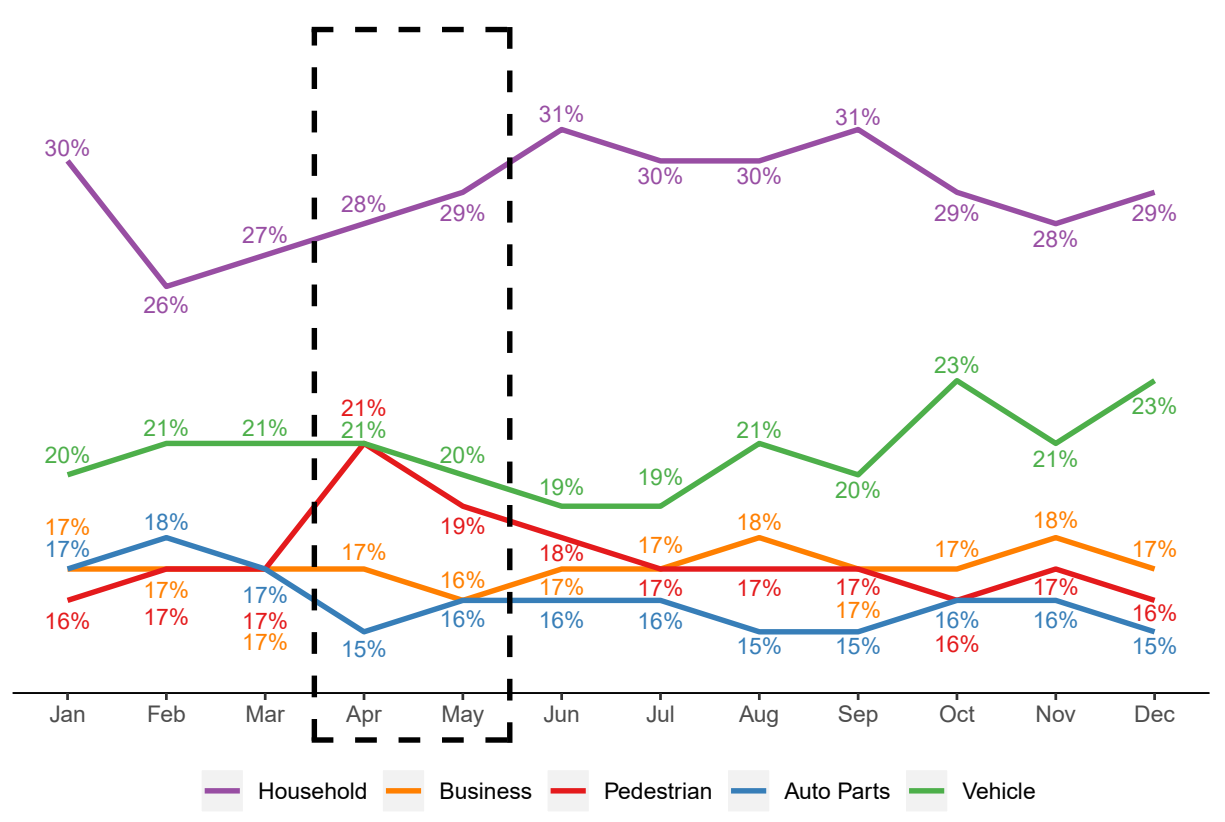

Figure 2. Temporal distribution of crime incidents for the state of Aguascalientes between January 2011 and December 2018. Dates spanning the Fair are indicated.

Because of the interest the Fair sparks on C4 operatives and authorities, they were interested in knowing if there were any important deviations from this behavior around the Fair grounds. Table 3 shows the same percentages for the central region of the City of Aguascalientes. 
Table 3. Percentage of occurrence for crime types in 2016 and all years in the central region of the city of Aguascalientes. Data from C4 and the Attorney General criminal incidence data set.

\begin{tabular}{lcc}
\hline Type of Crime & Percentage in 2016 & Percentage in 2011-2018 \\
\hline Carrier theft & $0.04 \%$ & $0.02 \%$ \\
Individual transport theft & $0.62 \%$ & $0.49 \%$ \\
Public transport theft & $0.37 \%$ & $0.90 \%$ \\
Recovered objects & $1.48 \%$ & $1.14 \%$ \\
Other thefts & $6.22 \%$ & $6.12 \%$ \\
\hline Household theft & $7.62 \%$ & $10.37 \%$ \\
Business theft & $14.70 \%$ & $14.82 \%$ \\
Auto parts theft & $16.06 \%$ & $18.16 \%$ \\
Pedestrian theft & $23.51 \%$ & $23.82 \%$ \\
Vehicle theft & $29.39 \%$ & $23.83 \%$ \\
\hline
\end{tabular}

Although there are some noticeable differences in how crime types are ranked, the five crime types that occur more frequently are the same in the central region and throughout the state. Once the temporal nature of the data is taken into account, it is seen that the first ring around the central part of the city, where the Fair takes place, has a very distinctive behavior. Figure 3 shows that in April and May, the months of the Fair, pedestrian incidences experience a high increase from around $25 \%$ to about $35 \%$. Afterwards, they return to their normal rate.

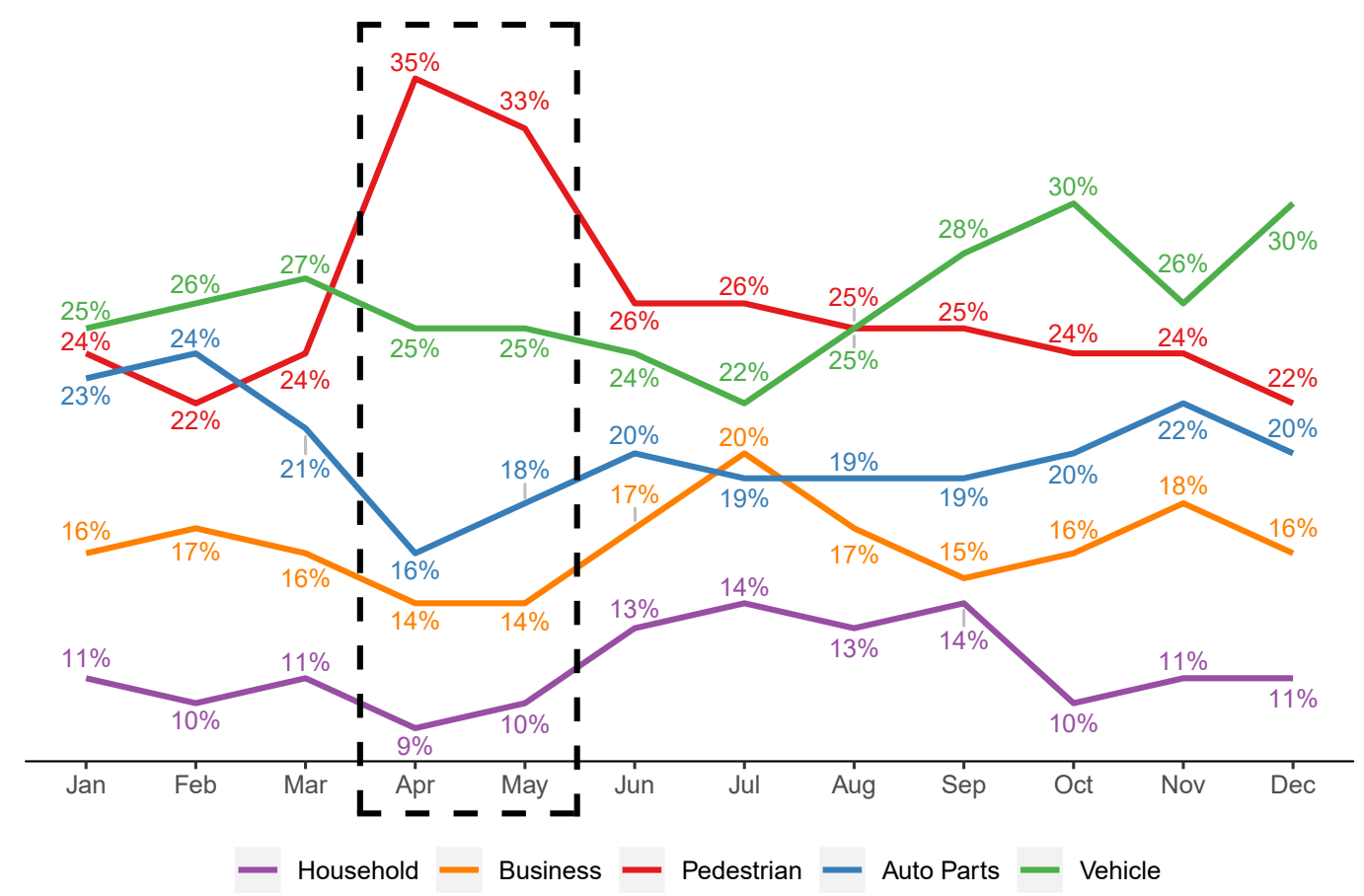

Figure 3. Temporal distribution of crime incidents inside the first ring of the City of Aguascalientes, near and around the Fair grounds, between January 2011 and December 2018. Dates spanning the Fair are indicated.

After presenting these initial statistics to $\mathrm{C} 4$, it was made evident that crime incidence during the Fair shows a distinct behavior. Granted all types of crime are relevant to improve citizen's conditions in the city, after discussing interests and priorities with C4 authorities and operatives, they turned their focus and attention to four main categories of crime for subsequent analyses, namely: pedestrian, vehicle, business, and household incidents. They requested to leave incidents related to auto parts out. 
With just these four categories, a density map of the incidences over the whole state conveys the powerful message that most of the crime does indeed occur in and around the city center. Figure 4 shows a simple kernel density estimator map with a search radius and $x$ and $y$ pixel sizes all of $\approx 100 \mathrm{~m}$. This length was chosen as it represents the typical size of a city block. Although there are some high-density patches outside the first ring, it can be seen that it makes sense to focus on what is going on near the city center.

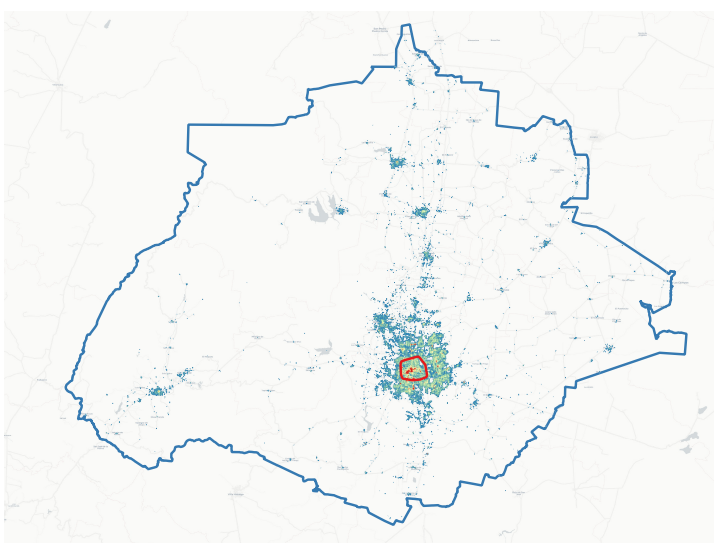

(a)

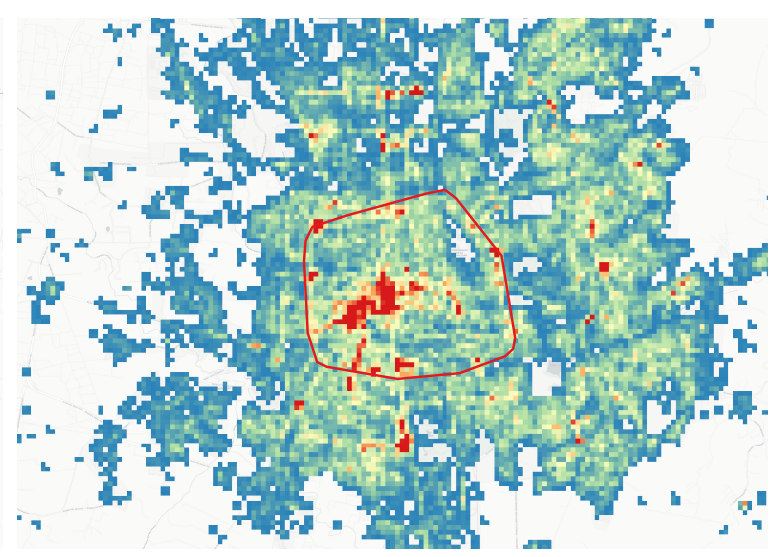

(b)

Figure 4. (a) Spatial distribution of the density of crime incidents in the state of Aguascalientes. (b) Spatial distribution of the density of crime incidents inside the first ring of the City of Aguascalientes, near and around the Fair grounds. Density was calculated using data between January 2011 and December 2018. Red values indicate higher concentration of crimes over the time period while blue ones indicate less concentration.

\subsection{Proposed Approach}

After the initial data exploration and decision of focusing on four main types of crimes, the idea of a risk map, an online map that would help visualize the spatio-temporal behavior of crime, was pitched to the C4. The idea was well received and development was made using open-source software to avoid incurring in hefty fees the institution would then have to absorb in order to keep the map running and continue to be usable by $\mathrm{C} 4$ operatives and personnel. The idea of approaching the development framed within the scope of geovisual analytics was helpful in terms of visually analyzing large amounts of geographic data and help uncover interesting and unknown patterns.

Early attempts at bringing together time and space in Geography can be dated back to the mid-1960s with the work of Hägerstrand [46,47] and the process of diffusion through space over time. Efforts to incorporate time and space into the geographic realm in innovative and dynamic ways were already put forward at the end of the 19th century $[48,49]$ and were finding a niche to become a more common topic of discussion, development, and academic debate. The need for "data mining, database processing, optimization, and other computational methods for utilizing and emphasizing the temporal characteristics of geographic information in rich, novel, and useful ways" has been pointed out [26] and several studies have proposed innovative techniques to help reveal patterns based on the spatio-temporal variation of different kinds of movement data [50-52]. In terms of space, time, criminal incidence, and patterns, some authors have proposed different approaches to implicitly or explicitly incorporate the time dimension in maps and visualizations [53-56]. Some others explore the use of space-time cubes to study clustering of crime events [57], focus on the statistical and methodological aspects of working with spatio-temporal crime data without elegant visualizations or animations [58,59], or asses and visualize spatio-temporal clustering of crime events at a regional level [60]. 
For the case under consideration, the risk map aims at providing means to analyze the historic situation of public safety in the state. By showing the evolution of crime incidence over space and time and being able to detect patterns and trends, it would help shed light about setting priorities and delimit geographical areas with the highest concentration of crime according to different data sets provided by different entities. Detected time patterns combined with spatial patterns can be helpful in deciding when, where, and how to allocate resources ([25], (Chapters 9 and 10)) ([61], (Chapter 3)). Additionally, it would provide statistical and geographical analysis of the evolution of crime incidence to identify crime types and critical times and regions that may require more attention from different public safety instances at the local, state, and federal level.

The map was initially developed as an interactive online map, not a full-fledged mapping platform, as data was being fed into the system from other sources and consumed by the map. Rather, as mentioned above, its purpose was to help visualize patterns through space and time. Crime incidence was displayed both as points and densities, as clusters of data points give a much better sense of the level of incidence in a particular region. Given the date inconsistencies present in the provided data sets, these were standardized as YYYY/MM/DD.

As mentioned before, the initial online risk map was developed using free and open source software and tools. Leaflet JS (https:/ / leafletjs.com/) was used as the mapping library and users can choose to display base maps from Carto Light, Carto Dark or OpenStreetMap tiles. Other contextual layers were also included as overlays in order to provide users with additional layers of information that may be of relevance when analyzing crime incidence. Table 4 lists the 16 supplementary overlays included in the map. These were served as WMS layers using GeoServer.

Table 4. Sixteen additional overlays for the Aguascalientes risk map to include basic cartographic information and points of interest.

\begin{tabular}{ll}
\hline Layer & Type \\
\hline Average number of occupants in single-room households & Polygon \\
Average number of occupants per room in private households & Polygon \\
Average number of occupants in households with female leadership & Polygon \\
Unemployment rate & Polygon \\
Average number of occupants in private households & Polygon \\
Population density per km² & Polygon \\
Population density per block (ha) & Polygon \\
Roads on block with street lights (\%) & Polygon \\
Roads on block with semi-fixed street vendors (\%) & Polygon \\
Roads on the block with street street vendors (\%) & Polygon \\
Schools & Point \\
Banking institutions & Point \\
Illegal businesses & Point \\
Convenience stores & Point \\
Aguascalientes municipal boundary & Polygon \\
Aguascalientes municipal police sectors & Polygon \\
\hline
\end{tabular}

The back-end for data storage is PostgreSQL (http:/ / www.postgresql.org) coupled with PostGIS, a spatial database extender for PostgreSQL (https://postgis.net) that allows location queries to be run in SQL. The front-end was developed using Bootstrap (http://getbootstrap.com) and jQuery (https://jquery.com). Server-client communication is done with PHP (https://www.php.net) to retrieve data from the back-end and dynamically display it on the front-end. The local development version can be accessed at http:// dev.centrogeo.org.mx/ags.

In order to take into account the spatio-temporal nature of crime incidence data sets, a suitable way to display data points that vary over time and space was needed. Leaflet's TimeDimension plugin was a suitable solution since it allows adding "time dimension capabilities on a Leaflet map" (https:/ / github.com/socib/Leaflet.TimeDimension), meaning it is possible to display points on the 
map based on a given date or time frame. The plugin already includes functionality to add a control bar to the map with play, pause, next, and back buttons together with other customizations.

On load, the map displays the last month of available data from the data base for pedestrian incidents, is zoomed in around the city of Aguascalientes, and the time dimension control is set to display data per day. Users can choose between different crime types (pedestrian, vehicle, business, and household) and time periods (daily, weekly, and monthly). Due to the temporal behavior of crime and given the Fair lasts about three weeks each year, it was deemed reasonable and useful to aggregate data for different time periods in order to help detect peaks of criminal activity. At any moment users can zoom in or out or pan the map. Additionally, a heat map is displayed to show the density of the chosen crime type in the area. The heat map is calculated using a smoothing radius of $\approx 500 \mathrm{~m}$. In order to improve the users' visual experience, individual data points are only showed if users zoom in enough. At the bottom of the map, an animated bar chart displays the number of incidents for the selected crime, time period, and selected dates. Bar widths are calculated in order to provide he best fit depending on the selected time period and start and end dates. The maximum bar height is constant, but the vertical scale is updated to reflect the number of incidences in the selected period. TimeDimension's control is located in the bottom left corner of the map. Clicking the play button triggers several actions: Asynchronous JavaScript and XML (AJAX) calls are made for each time step in order to retrieve the corresponding data from the database as a JSON response, data points are updated on the map, and both the heat map and the bar chart are updated. Figure 5 shows the initial screen of the risk map for Aguascalientes.

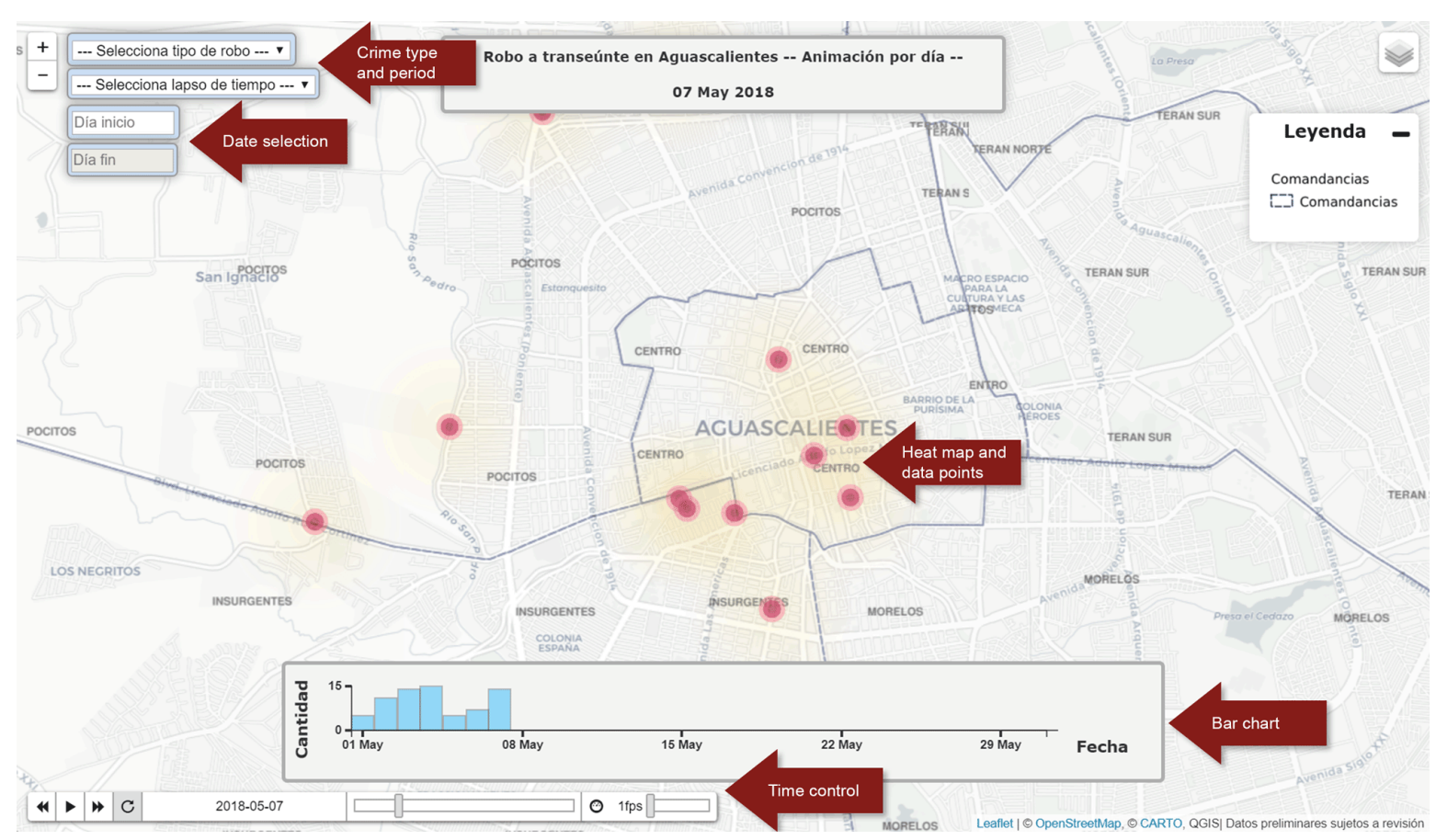

Figure 5. Initial design of the Aguascalientes platform showing type of crime, time period and date selectors together with heat map, data points, bar chart, and time dimension control.

After presenting a functional risk map, C4 requested that some other vector layers were added. These included the geographic location of panic buttons, shot microphones, license plate readers, IMP (Intelligent Monitoring Point) and PTZ (Pan-Tilt-Zoom) cameras. They wanted to see how their infrastructure was deployed on the field and what sort of coverage they could obtain from it. These layers were styled using FontAwesome icons (http:/ / fontawesome.github.io/Font-Awesome).

C4 is in charge of dispatching emergency calls (911) and its operatives were interested in seeing how criminal incidence extracted from these records compared to data from the Attorney General. In order to compare the general behavior of these different data sets, a new module that allowed 
comparing different heat maps at the same time was developed. Unlike the risk map, this one did not incorporate the time dimension as the interest was in the overall similarities or differences between data sets. Eventually, a third data source from the State Public Ministry of Public Safety was included. Figure 6 shows the comparison of these heat maps.

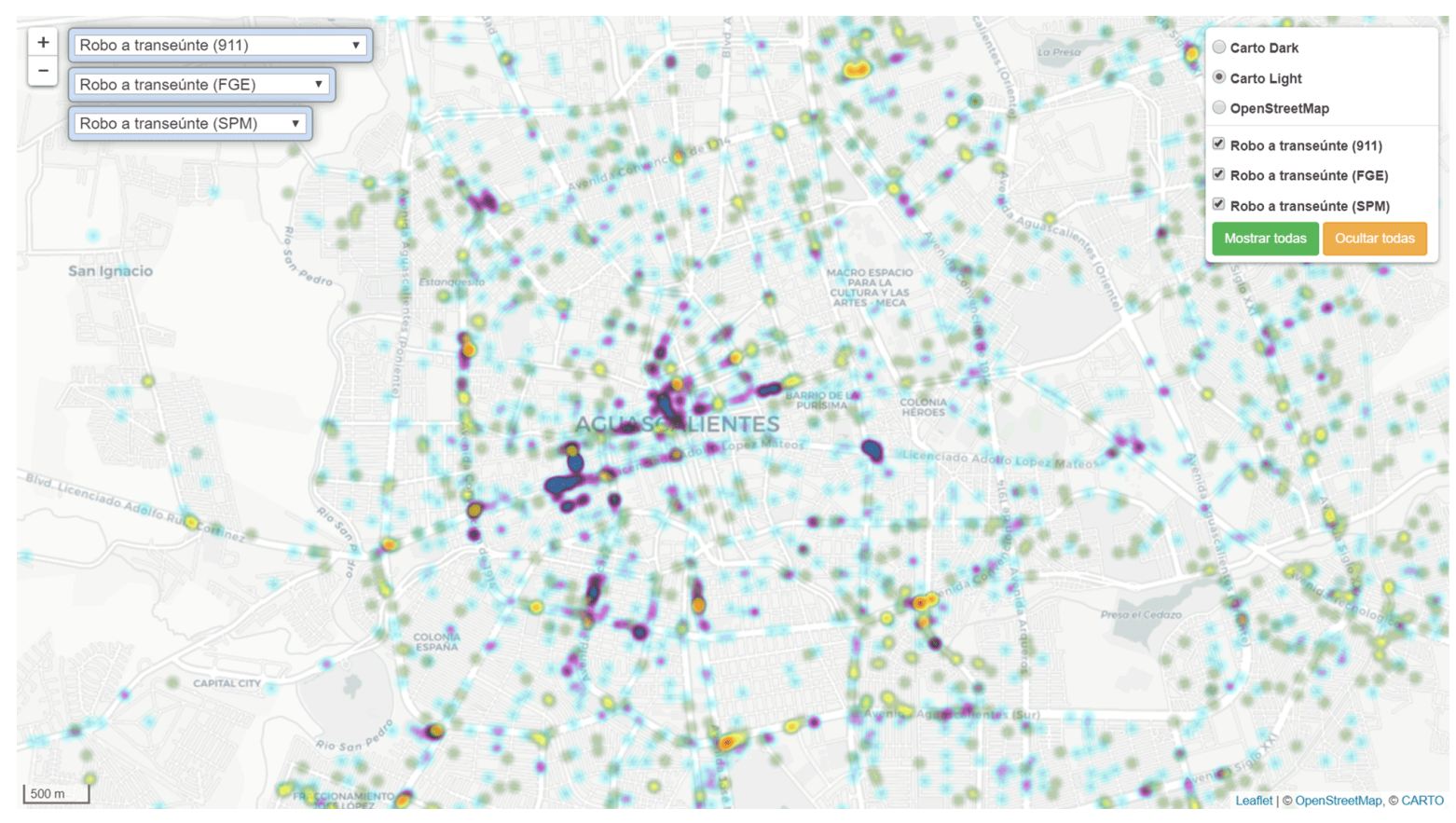

Figure 6. Heat maps showing different data sets for theft incidence in 2017 in the city of Aguascalientes.

In order to compare how the state of Aguascalientes is ranked with respect to the national averages, data from the Executive Secretariat of the National Public Security System was presented as a time graph for different crime types. The aim of this visualization is to show the evolution of crime incidence over time. Figure 7 shows a graph that helps compare the crime incidence for the state of Aguascalientes and the whole country since 2011. A dual axis chart where the left (blue) axis indicates the scale for the Aguascalientes data series and the right (green) axis indicates the scale for the whole country data series was used.

As it is common to get confused with scales and series while reading dual axis charts, care was taken to use different colors that were easily recognizable by operatives. In particular, data for the state uses a blue color that is associated with the current government (as can be attested by visiting their website). Data for the country are colored in green (as a reference to the first color in the national flag). On the top right is a drop down list that lets the user select the type of crime to visualize in the graph. If data is such that lines intersect, users are cautioned to be attentive of the colors, scales and axes to properly interpret each series and be aware that intersections do not mean data values are the same. The horizontal lines represent the average values over time for each data set.

Side-by-side or indexed charts could be also explored, but the disadvantage of the former is that placing two charts next to each other another would play against glancing at all the data at once; the advantage of the latter is that it is more aesthetically pleasing, but the disadvantage is that operatives find it more useful to have the actual values of crime incidence rather than the relative change from a base number. 


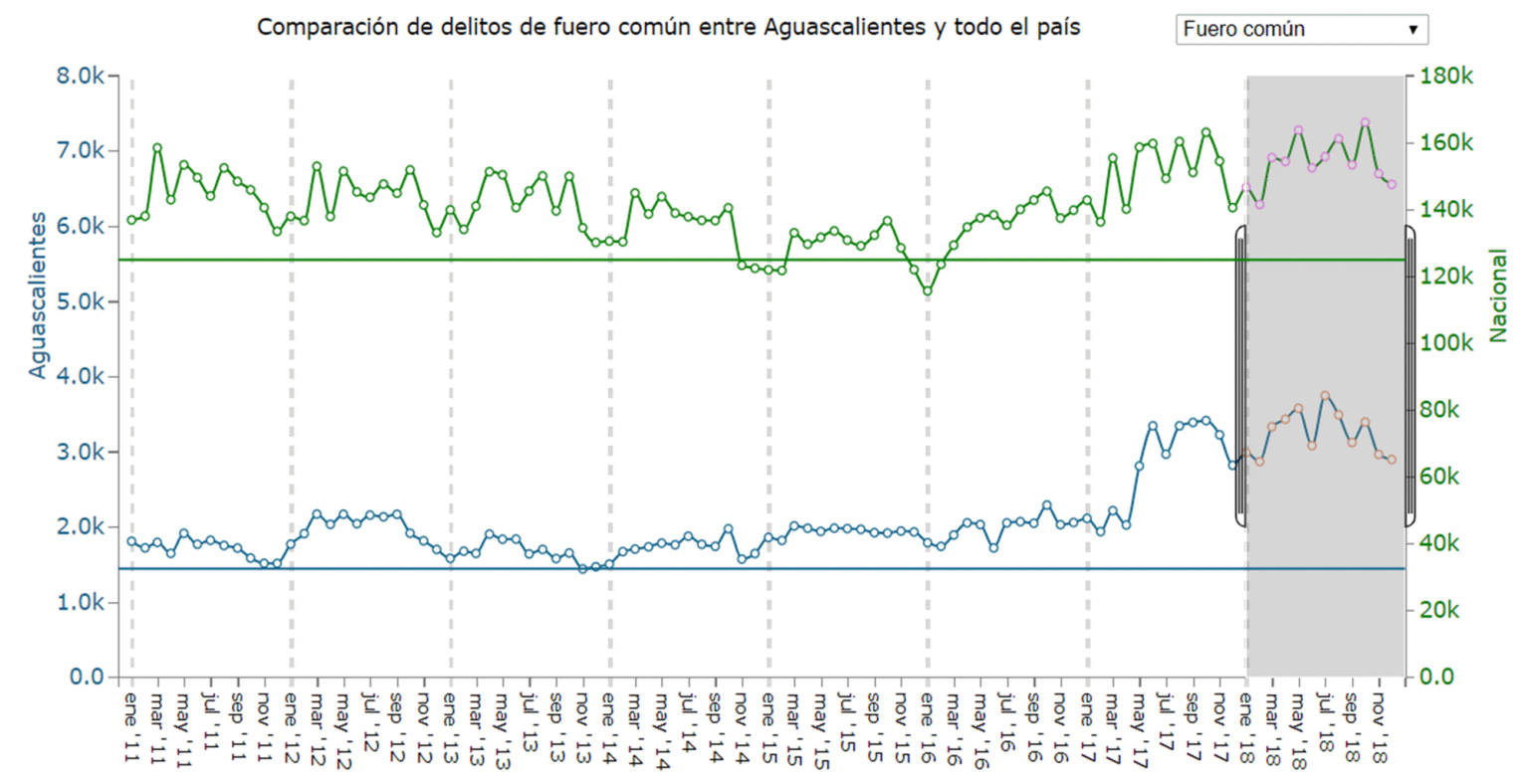

Figure 7. Time graph for crime incidence. The left axis is the scale for the state of Aguascalientes and the right is for the whole country. Horizontal lines represent average values. Data from the Executive Secretariat of the National Public Security System.

An additional module was developed that, by means of a simple yet powerful visualization, charts and tracks the efficiency of different police sectors over time. The $x$-axis represents the efficiency of each sector expressed as the percentage of the rate of detainees over the number of crime incidents, namely, $E=\frac{\text { detainees }}{\text { crimes }}$. Higher efficiency values mean the police sector is doing a good job in bringing in suspects of crimes. The $y$-axis represents the number of crime incidents. Each police sector is plotted with its corresponding $(x, y)$ coordinates in this scatter plot. Each dot is colored in accordance to the background of the plot subdivisions. Red means poor efficiency; yellow means medium efficiency; green means good efficiency. Hovering on top of a dot shows its values for the currently displayed year. Clicking the play button in the toolbar triggers an animation that changes the year together with the position of the dots. While changing the coordinates, dot colors are also updated if needed. Figure 8 shows a proof-of-concept of this chart. Part (a) shows data for 2014 and part (b) for 2015. It is interesting to note the changes for the TERAN SUR sector. It lowers its efficiency and goes from being ranked as good to regular. Unfortunately, a far better use of this chart is yet to be achieved due to the lack of data from both the Attorney General and C4 to update the efficiency values for the rest of the years. It can be seen, however, that with data available at different times scales, and even geographical ones, this chart becomes a pretty useful tool in keeping track of how different police sectors are performing. The chart automatically calculates and fits the best limits to display all data values across all available years so as to provide a good user experience.

A third module involves the development of a heuristic algorithm to dynamically propose an initial distribution of video surveillance cameras in the city of Aguascalientes that takes into account the historical incidence. This heuristic algorithm draws ideas from the Maximal Covering Location Problem (MCLP) and the Backup Coverage Location Problem (BCLP) on how to approach sensor placement regarding coverage and overlapping, two conflicting objectives, while expecting the obtained solution will be of high quality, albeit not necessarily optimal [62,63].

Using a road network to define street corners as potential locations, crime incidence is retrieved from the database and a density map is built on-the-fly using a search radius of $\approx 275 \mathrm{~m}$ and a cell size of $\approx 80 \mathrm{~m}$. The search radius is related to how far, according to city officials, a typical surveillance camera can identify objects, and the cell size closely resembles a typical city block. Areas with values of 2 standard deviation or more above the mean are masked out, extracted, vectorized, and used to 
constrain the locations of potential cameras. As a first exercise, the local government asked to test the placement of 200 cameras. Some assumptions, however, needed to be made. The first is the more realistic one that cameras are useful to discern objects up to $100 \mathrm{~m}$; the second is that cameras have a field of view of 360 degrees. In order to reduce redundancy of selected corners, the Jaccard index of similarity [64] (or intersection over union) defined as $J(A, B)=\frac{|A \cap B|}{|A \cup B|}$ is used. By creating circular buffers around locations and defining a maximum overlap of $25 \%$, by means of an iterative process, some of the camera locations that satisfy the condition $J(A, B)<0.25$ are kept. Additionally, cameras that see more incidences in their $100 \mathrm{~m}$ vicinity are ranked higher than those that see less and are thus preferred.

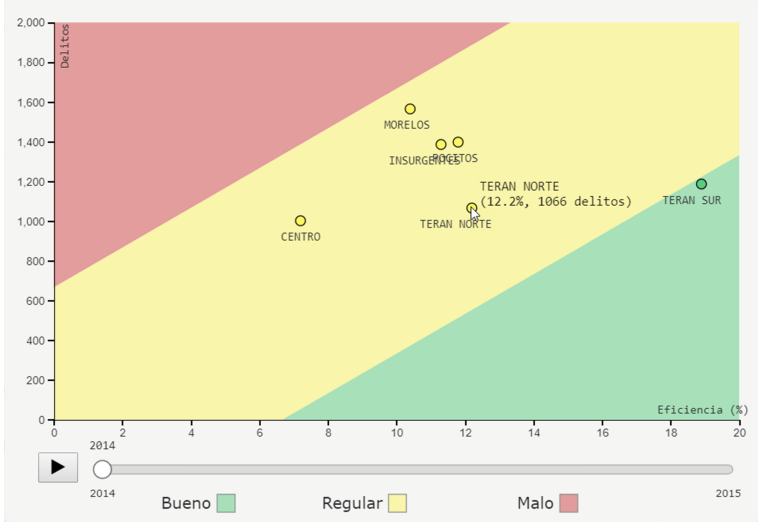

(a)

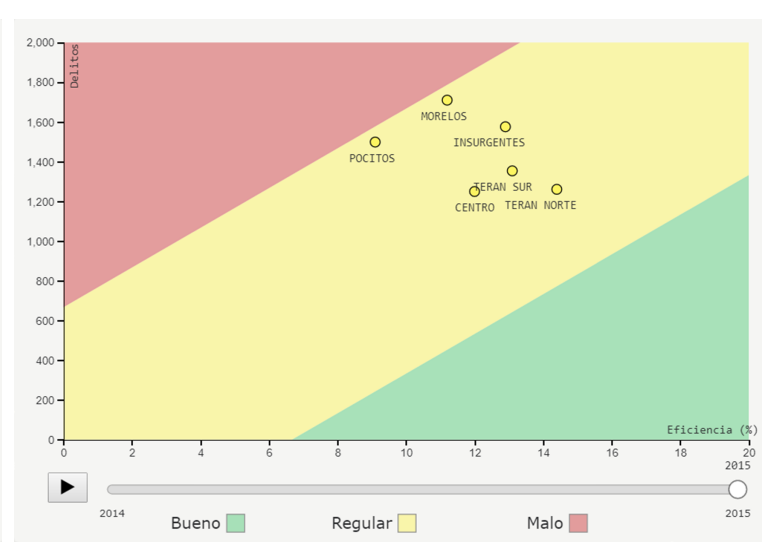

(b)

Figure 8. Proposed efficiency chart for police sectors. (a) Efficiency for 2014. (b) Efficiency for 2015. Note how the TERAN SUR sector crosses boundaries and is classified accordingly.

The Law of Crime Concentration states that for microgeographic units (such as addresses, facilities, street segments, or small clusters of street segments), crime concentrates within a narrow bandwidth $[65,66]$. A city can have many of these micro places, often referred to as "hot spots" of crime [67]. Studies in Criminology seem to agree that crime concentration is stable over time and that hot spots are not likely to disappear in short periods of time if there is no intervention $([66,67]$, and references therein). So, detecting these regions that prevail over time, might help pinpoint locations suitable for action that may have positive benefits in the short and long terms [67]. In this sense, the goal is to place cameras where there is a historically higher criminal incidence, pervasive hot spots that, if intervened, could lead to amelioration and reduction of clustering in such areas, thus creating a "positive snowball effect" to help reduce crime.

Once these locations have been found, they can be put on an interactive map and operators can explore how many incidences that particular camera could historically see. Care needs to be taken as it is clear these numbers are calculated using a circular buffer and cameras cannot see through city block or buildings. A second iteration of this module would improve this approach and count these observations using isovists.

Although at times the use of video surveillance systems seems to be guided not towards prevention but rather to discourage criminals to act, because they can be recorded and maybe get caught [68], some studies recognize its usefulness in reducing incidence for certain crime types. Piza et al. [69] review several studies in different cities and countries and report that the use of video surveillance can be associated with a slight decrease in crime (about $13 \%$ in property, $14 \%$ in vehicle, $20 \%$ in drug, and $5 \%$ in violent crimes). Another study finds that video surveillance feeds were useful in solving $65 \%$ of the cases of crimes recorded on the British Railway System in which they where available [70].

However, operators would need to be lucky in order to see the right camera feed at the right time in order to detect something unusual going on at that moment an potentially trigger an operative. 
It is possible, however, to use a probabilistic approach to try and let operators know which cameras they should see at what times and days. By creating a schedule plot with 6-hour time breaks on the $y$-axis and days of the week on the $x$-axis, for a total of 28 cells, it is possible to color-code a grid that shows whether a particular day and time frame shows a higher probability of something occurring. With a traffic-light color scheme, it is easy to understand that red cells (days and times) have high counts, yellow have medium counts and green have low counts. All the cameras could be automatically checked at different time intervals to let operators know what cameras should be monitored throughout the day. It is important to note, however, that in this implementation the intervals are split by quantiles and the same color scale is applied to every camera. Users should be careful when reading this graph as the texts underneath the legend are updated to reflect the values they represent. This particular functionality is shown in Figure 9a. Clicking on a different camera updates the cell distribution, the legend texts, the camera ID, and its indicator. The indicator is the weighted sum of the number of cells defined as

$$
I=\sum_{i} 3 \cdot c_{h}+\sum_{j} 2 \cdot c_{m}+\sum_{k} c_{l}, \text { with } i+j+k=28,
$$

where $c_{h}$ is the number of cells with high (red) values, $c_{m}$ the number of cells with medium (yellow) values and $c_{l}$ is the number of cells with low (green) values. I can take values between 28 (when all cells are green) and 84 (when all cells are red). To make this indicator more readable, a straightforward normalization is used to get values between 0 and 1 . Thus,

$$
I_{N}=\frac{I-\min (I)}{\max (I)-\min (I)}=\frac{I-28}{56} .
$$

This indicator gives a rough idea about how bad the location is: the closer its value is to 1 , the worst it is, because many hours and days have many observed crime incidences. Additionally, whenever the user hovers the pointer on each cell of the schedule plot the count of the number of crime incidences for that day and time is displayed.

This module also has the capability of simulating what would happen if a new event was added to the data base. By clicking anywhere on the map, a real time event is simulated and a marker is added to the map along with three colored rings: a $100 \mathrm{~m}$ red one, a $250 \mathrm{~m}$ yellow one, and a $500 \mathrm{~m}$ green one. When the user clicks on the map and the marker is added, the existing cameras are queried to see if they intersect any of the rings and are colored in accordance to their distance to the simulated event: red if they are within $100 \mathrm{~m}$, yellow if they are between 100 and $250 \mathrm{~m}$, and green if they are between 250 and $500 \mathrm{~m}$ of the event. This gives an interactive playground to test how a crime incidence could be detected by the proposed camera locations, and could serve to set up a security perimeter and focus on certain cameras if the event deserved it. An example of this functionality is shown in Figure $9 \mathrm{~b}$.

The fourth and last additional module takes the proposed camera locations and simulations one step further by using them to trigger alerts by detecting which cameras could be used to set a monitoring perimeter for carjacking incidents. As a proof-of-concept, the module consists of a digital map initially centered on the city of Aguascalientes, showing the proposed cameras with a time dimension control to change the date at the bottom left, which can take values from 1 January to 31 December 2017. This time around, instead of querying the database every time, data is only read once at the beginning, returned as a GeoJSON FeatureCollection, and filtered by comparing each feature's date property with the control's value. When they match, the feature is displayed on the map together with the three rings used in the previous module. Similarly, if a proposed camera is contained within any of the rings, it is colored accordingly. Additionally, the nearest neighboring cameras are calculated for each event by using $k$-nearest neighbors with $k=15$, and a maximum search distance of $5000 \mathrm{~m}$. This module is useful for showcasing the geovisual analytics capabilities of the platform that could be exploited for real-time events, if they were being added to a data base. If the platform 
was adopted and used to monitor cameras in real time, instead of seeing what cameras could have been useful to track some event, it could provide real time suggestions on what cameras the operatives should turn their attention to. However, because by design there is no total coverage of the streets, it is possible to find events without cameras nearby. Figure 10 shows two examples of carjacking events together with their nearest cameras: one with a case when cameras are within range to be useful and they are colored according to the ring in which they are contained and another when there are no nearby cameras.

Similar to the efficiency chart, this module needs to be further exploited and its usefulness tested in full due to its using carjacking data only for 2017. Nonetheless, it is an important part of the prototype that contributes to the ample spectrum of applications and analyses that could be achieved if data were available and up to date.

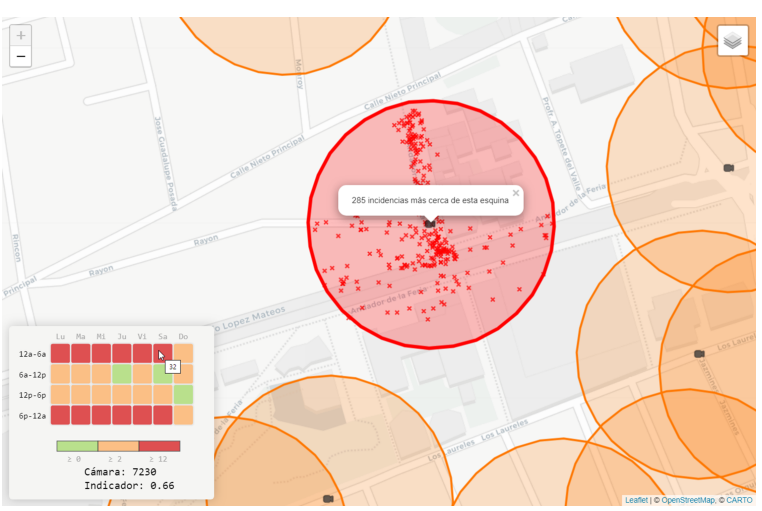

(a)

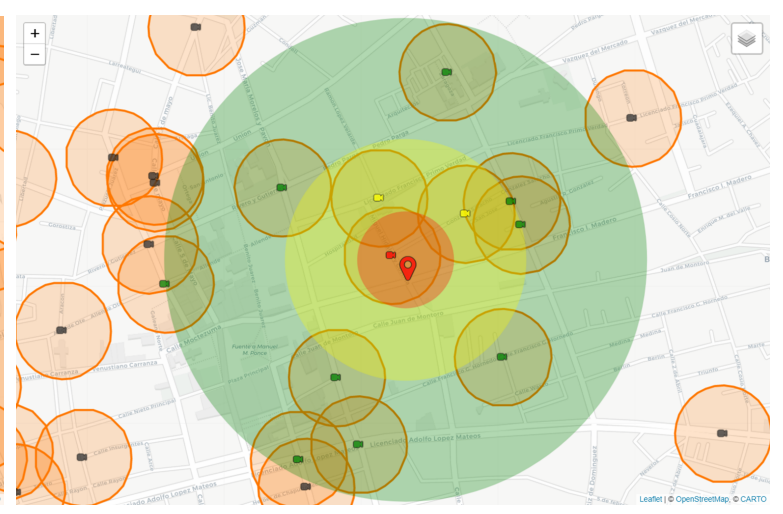

(b)

Figure 9. (a) Example of a selected camera with its associated schedule plot. Hovering the pointer on each cell shows the number of observations for a given day and time frame. The black camera icons represent the proposed locations of video surveillance cameras. The orange shaded circles represent the area each camera can cover. The red shaded circle corresponds to the selected camera. Additionally, a popup indicates the number of occurrences that camera would have historically captured. Small red crosses show the locations of the events that camera would have detected. The indicator at the bottom of the plot takes values between 0 (better area) and 1 (worse area). (b) Example of a simulated real-time event and cameras around it. The red marker is the location of the simulated event, the red camera is contained within a $100 \mathrm{~m}$ radius, the yellow cameras are contained between 100 and $250 \mathrm{~m}$, and the green cameras are contained between 250 and $500 \mathrm{~m}$ of the event.

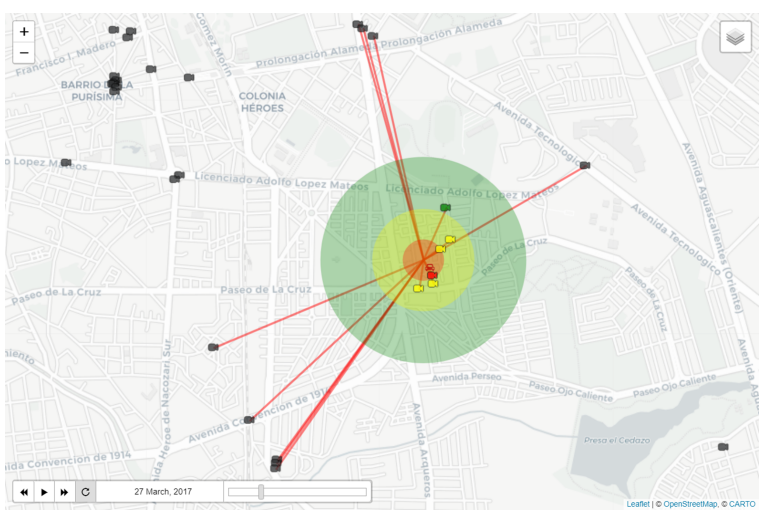

(a)

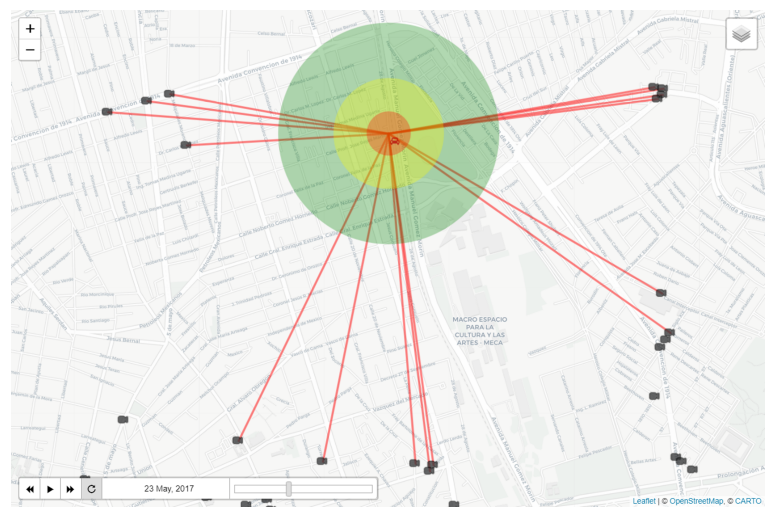

(b)

Figure 10. Example of an alert triggered for a carjacking event. The red car marker is the location of the actual event. Cameras are highlighted in containing rings and some other nearby cameras are also shown. (a) A carjacking event with surveillance cameras nearby useful for creating a perimeter around the event. (b) A carjacking event without surveillance cameras within $500 \mathrm{~m}$. 


\section{Results and Discussion}

This research project set out to build a simple online map that would allow operators to study the spatio-temporal dynamics of criminal incidence in the state of Aguascalientes, Mexico. It quickly escalated to a far more substantial online application that encompasses six different modules. With them, users can: (1) explore the spatial distribution of different crime types along different time scales; (2) compare density maps for three different sources of crime incidence in the state; (3) compare the average criminal incidence levels of the state to the national ones; (4) visually analyze the efficiency of police sectors; (5) visually analyze the historical probability by day of the week and time of day of events occurring on a certain surveillance camera and simulate a real-time event on the map that could be followed with some cameras; and (6) explore the possibility of following a particular event (e.g., carjacking) with the surveillance camera set up by locating the nearest cameras.

This paper reports the results from 2016 to 2018. The ongoing project started in 2016 and shortly after the first online map was made available to the authorities, they were already planning actions for next year's Fair. Indeed, it can be seen that there was a reduction of crime near the Fair grounds. Figure 4 shows that the highest concentration of crime occurs inside the first ring of the city. Focusing on this area, a summary of the number of incidences inside the first ring and in the whole state, both during the Fair and throughout the whole year, is shown in Table 5.

Table 5. Number of crime incident reports for each year in Aguascalientes. Top portion shows reports and percent change with respect to the previous year during the Fair dates in the whole state and inside the first ring. The bottom portion shows the corresponding data for all year for the whole state and inside the first ring.

\begin{tabular}{llcccc}
\hline & Year & $\mathbf{2 0 1 5}$ & $\mathbf{2 0 1 6}$ & $\mathbf{2 0 1 7}$ & $\mathbf{2 0 1 8}$ \\
\hline \multirow{4}{*}{ During Fair } & In state & 541 & 633 & 589 & 846 \\
& Percent change & - & $\mathbf{1 7 . 0 1} \nearrow$ & $-6.95 \searrow$ & $43.63 \nearrow$ \\
& Inside first ring & 212 & 271 & 170 & 265 \\
& Percent change & - & $27.83 \nearrow$ & $-37.27 \searrow$ & $55.88 \nearrow$ \\
\hline \multirow{4}{*}{ All year } & In state & 7318 & 7744 & 10,745 & 11,244 \\
& Percent change & - & $5.82 \nearrow$ & $38.75 \nearrow$ & $4.64 \nearrow$ \\
& Inside first ring & 1701 & 1827 & 2131 & 2120 \\
& Percent change & - & $7.41 \nearrow$ & $16.64 \nearrow$ & $-0.52 \searrow$ \\
\hline
\end{tabular}

By looking the reported incidence per year and comparing it to what happened inside the first ring near and around the Fair during the year, it is possible to shed some light into what may have happened. Both 2016 and 2018 have a similar behavior during the Fair and throughout the year: they show an increase of criminal incidence both at the state level and inside the first ring of the city. It is interesting to note, however, that 2017 shows a decrease during the Fair but an overall increase in the year, which supports the assumption that authorities may have been more attentive during the Fair. Even if it is not desirable to have such changes in criminal incidence, this result is at least an indication that the explicit use of criminal locations inside the first ring served its purpose. It is likely that specific problematic locations were identified using the tools provided throughout this project, and actions were taken that helped reduce crime incidence, albeit only for the duration of the Fair. The behavior for 2018 can be partially explained when one takes into account that it was a particularly bad year for the whole country. Nonetheless, it is difficult to ascertain what actions where put in place in 2017 that may have aided in its decrease. There have been petitions to the state counterpart on several occasions to try and gain insights into these possible actions, but to no avail. 
By exploring the temporal distribution of crime incidence throughout the year and during the Fair it is possible to attest that focus seems to have been the Fair. Figure 11 shows these trends. It can be seen that during 2016 there was a high number of pedestrian-related crimes during the Fair that appear to be greatly reduced in 2017 and have an increase in 2018, both at the state level and inside the first ring. However, there is still need to further analyze other possible causes of increasing incidence outside of the Fair duration. For instance, explore what other events might occur towards the end of October that trigger more household thefts or pedestrian incidents during this time.

By successfully bringing together the spatial and temporal nature of criminal data into one dynamic map, it was possible to identify locations inside the first ring of the city that are prone to historically accumulate more observations over time. This, as far as can be told from the analysis that was carried out, was helpful in determining actions that improved on-site conditions from 2016 to 2017. As was mentioned before, 2018 was a particularly bad year overall, but it would be useful to know what led authorities to implement certain actions during 2017 to better understand how the proposed approach can be improved.

This research was not initially intended to be presented as a dashboard for the authorities to analyze data and use it to draw conclusions and make decisions. At first it was only meant to show the spatio-temporal distribution of crime by means of a risk map. It was later on that it became something more. In this sense, looking into the future, it would be convenient to make operatives and authorities sensible about the drawbacks they are falling into and make them aware of how collaborating around a common task would greatly improve their outcomes. If the matter that apparently each institution is working for itself was overcome and data was shared in a standardized notation and in accordance to official catalogs, it would be far easier to turn this initial platform into a more robust one that would tend towards showing trends and alerts as soon as data was updated, which would ideally be on a daily basis. Furthermore, with feedback from authorities and operatives, it could be developed into a far more useful dashboard with the purpose of providing the views and statistics they require or desire.

This platform was part of a more extensive report submitted to the 3rd National Competition of Best Police Practices Based on Evidence and was awarded the 2nd place in the "Crime Prevention" category. This encourages its further development in order to provide the state government and local authorities better tools that can serve them in their everyday activities in improving the quality of life and public safety of the citizenry.

The efficiency chart is an interesting proposal that aims at creating a feedback loop within the context of police sectors and their administration. By tracking the progress every police sector has over time, it is possible to have indicators that are related to the performance of the city in terms of public safety. Apart form this, these indicators can be used as inputs during the planning phase of the course of action of decision-making and potential reorganizing of police sectors in the city. 


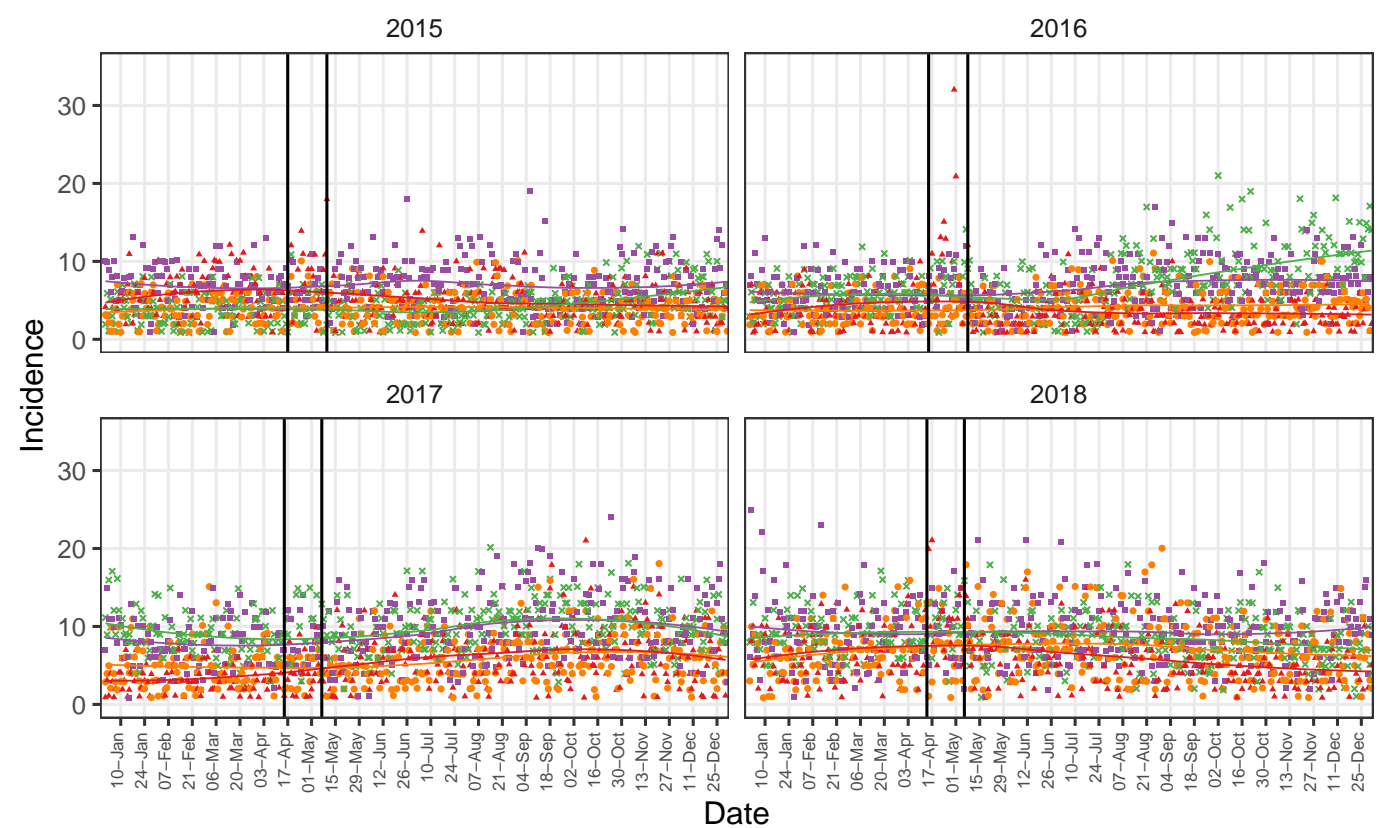

Crime Type $\rightarrow$ Household $\rightarrow$ Business $\rightarrow$ Pedestrian $\rightarrow$ Vehicle

(a)
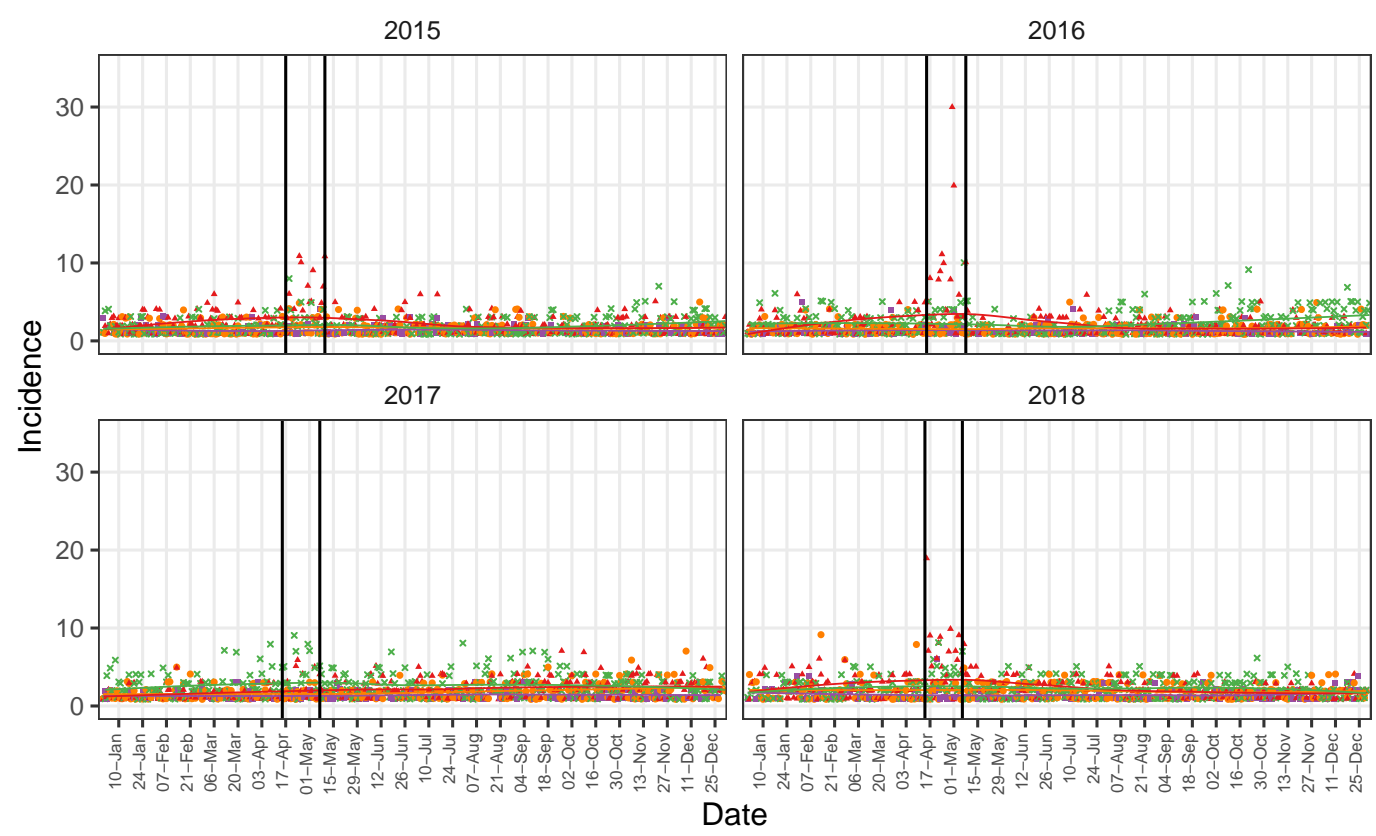

Crime Type $\rightarrow$ Household $\rightarrow$ Business $\rightarrow$ Pedestrian $\rightarrow$ Vehicle

(b)

Figure 11. (a) Time graph for crime incidence by year in the state. (b) Time graph for crime incidence by year inside the first ring. Vertical bars indicate the dates of the Fair. There are more than 30 pedestrian incidents during the Fair in 2016 that substantially decrease in 2017. 


\section{Conclusions and Future Work}

Academic work on smart cities has received more focus on governance, infrastructure, and mobility than public safety, in spite of its impact on urban life, planning, development, and management of the city. Nonetheless, the value and appropriateness of using ICT technologies to help with its management and decision-making processes are recognized. Although not necessarily from an academic or scientific standpoint, many local law enforcement agencies have put forward technological and procedural developments to support operative tasks. By focusing on public safety monitoring and management to help improve the well-being of both people and society and even allocate resources, they seek to bring together many different data sources under a common umbrella that are made available through urban dashboards.

The research reported here first deals with the experience of integrating and developing a dynamic and interactive exploration of criminal incidence that considers both the spatial and temporal dimensions. Delivered through different modules available to the local authorities of the Mexican state of Aguascalientes, they are designed to tackle the well-known spatial expression with the seasonal variability of crime. It was expected to be able to obtain spatio-temporal averages that help shed some light about the criminal dynamics in different periods of time and, obviously, in the territory. The provision of interactive interfaces and geovisual analysis was a fundamental and necessary component of this project. The idea was for the platform to read data in real-time, understood as changes experienced in the origin database being reflected within seconds in the platform. It is worth mentioning that this dependence in the data of origin has been one of the greatest pitfalls of the study. While not initially considered to be part of the prototype developed, additional modules where built to accommodate specific user needs that included:

- Developing an algorithm that takes into account the historical incidence to propose the location of a fixed number of surveillance cameras on the street network;

- With the proposed camera locations, identify which cameras need operator assistance on a particular day and time frame due to their historical likeliness of detecting an incidence;

- Simulating how a potential "security ring" could be created once a carjacking was reported in order to track the event;

- Create specific geographical an non-geographical visualizations of crime incidence.

In this sense, this research aims at establishing a geointelligence surveillance prototype in the State of Aguascalientes, Mexico. The first step is to explore the use of a digital platform to help provide local authorities with different elements in the context of the visualization and analysis of crime incidence in the State by means of a risk map and an information system to contribute strengthen security, response capacity, and performance of the state police while optimizing the use of existing information. The idea is for the prototype to provide the State Ministry of Public Safety with elements to make better decisions to improve safety conditions in the State, particularly during the National San Marcos Fair.

This research is relevant because the proposed approach looks into bringing together space and time, making it possible for decision-makers in the government of Aguascalientes to get the detail of where and when certain types of crime are occurring. Furthermore, the locations of surveillance cameras are proposed and proof-of-concept designs of an efficiency chart for police sectors together with a schedule plot are presented, followed by the simulation of real-time events and alert triggers of carjacking events.

By explicitly incorporating the temporal dimension of crime incidence into these geographical and statistical studies, the potential of using geovisual analytics in helping decision making processes of managing public safety can be seen. With it, it is possible to say something about how crime incidence behaves over time and space and thus, allows the discussion of how operatives could be planned to improve the situation. It also aims at using the results from these analyses to give authorities feedback on places and times that are problematic and need focus for a subsequent period. With this, the goal is on looking into a circular model of urban dashboards that involve data input, processing 
and visualization, generating output and indicators used in planning, and then have more data input that allow for continued analyses that yield further results (see, for instance, the smart city paradigm identified by Batty in [5]).

Having a way to visually monitor and easily assess and evaluate the performance of local police authorities is also relevant. The efficiency chart for police sectors is an interesting and useful proposal that still needs more data, preferably by month, to timely convey how police sectors are performing and show its true potential.

In terms of considering the integration of public safety as a pillar of a smart city framework, this study case suffered from drawbacks that provide useful lessons for its future development. A more open perspective inter-institutional communication and collaboration would greatly benefit and foster data sharing and flows of information to be efficient and more useful for the purpose at hand.

The fact that every data base update ran into issues of data compatibility, mainly due to date formatting and crime type specification, has been a constant concern throughout the project. Even though C4 personnel, who acted as intermediaries to mediate data exchange and provision, were alerted early on about these matters, they did not seem to care much about it and went on to provide updated data sets without caring to standardize them. This was interpreted as a lack on interest and, furthermore, as an overall and generalized attitude problem towards data sharing between different organizations and not feeling comfortable with getting remarks from an external observer. It would seem as if different agencies collecting data about public safety are working for and by themselves. Instead of creating synergies between them to improve societal conditions, they seem to be running against each other. Paying attention to this lesson has the potential to greatly improve how policies and decisions that affect citizens and society in terms of public safety are made.

As mentioned before, the proposed approach has some relaxed assumptions. Future work would look into incorporating more strict ones. One would be to account for criminal incidence around each surveillance camera so that irregular polygons that contemplate city blocks, buildings, or other types of visibility obstacles would be considered around each camera, instead of circular buffers. It would also be relevant to look into the possibility of including different camera models or adjust the area some cameras can monitor to incorporate more realistic assumptions of their geometry and coverage [71], instead of only consider cameras with a 360-degree field of view. Applying the proposed approach to a different city or location would also be beneficial to test the appropriateness of the general methodology in a different context. Namely, one that has different crime distribution over time and space, such as a larger city, or a region that has a data infrastructure that would allow updating data on a regular basis. This would also prove useful to test how the proposed indicator associated with the schedule plot behaves in different settings and would provide grounds to make adjustments, if necessary. In addition to this, testing new and innovative layouts that could show graphs, maps, and results in a more user-friendly or customizable way would also be suitable, together with a generalized way to present color ramps and classify values for the schedule plot.

Lastly, work will continue exploring the effects of institutional collaboration and how certain internal practices impact other settings, and how collaborative strategies can be further developed in order to guarantee a better data sharing scheme that enhances data use for better decision-making processes that affect both governments and citizens. Also, further research is needed in terms of looking into the relation between different ways to convey data visualizations through dashboards with viewers and authorities who may be impressed and even express interest and enthusiasm, but do not necessarily link them with a deep exploration of the problem at hand and even less with decision-making processes. The need to shed light on whether is a lack of interest, mistrust, inexperience or ignorance that permeates how actions are decided in these settings is of importance, as it would help clarify if there is a real opportunity of having incidence in these matters, what might be blocking evidence from being at the forefront of defining strategies, what would need to be done in order to break away from an inertial way of defining actions, if the appropriate counterpart is being chosen, or if there are other hidden interests at play. 
Funding: This research was partially supported by the Fondo Mixto (FOMIX) project AGS-2015-02-02-267835 between the Consejo Nacional de Ciencia y Tecnología and the State of Aguascalientes.

Acknowledgments: The author would like to thank the valuable comments and suggestions from the anonymous reviewers, which helped improve the original manuscript.

Conflicts of Interest: The author declares no conflict of interest.

\section{References}

1. Gibson, D.V.; Kozmetsky, G.; Smilor, R.W. Technopolis Phenomenon: Smart Cities, Fast Systems, Global Networks; Rowman \& Littlefield Publishers, Inc.: Lanham, MD, USA, 1992.

2. Chourabi, H.; Nam, T.; Walker, S.; Gil-Garcia, J.R.; Mellouli, S.; Nahon, K.; Pardo, T.A.; Scholl, H.J. Understanding Smart Cities: An Integrative Framework. In Proceedings of the 2012 45th Hawaii International Conference on System Sciences, Maui, HI, USA, 4-7 January 2012; pp. 2289-2297.

3. Cocchia, A. Smart and Digital City: A Systematic Literature Review. In Smart City: How to Create Public and Economic Value with High Technology in Urban Space; Dameri, R.P., Rosenthal-Sabroux, C., Eds.; Springer: Cham, Switzerland, 2014; pp. 13-43.

4. Serrano, W. Digital Systems in Smart City and Infrastructure: Digital as a Service. Smart Cities 2018, 1, 134-153. [CrossRef]

5. Batty, M. Inventing Future Cities; The MIT Press: Cambridge, MA, USA, 2018.

6. Allam, Z.; Newman, P. Redefining the Smart City: Culture, Metabolism and Governance. Smart Cities 2018, 1, 4-25. [CrossRef]

7. Neirotti, P.; De Marco, A.; Cagliano, A.C.; Mangano, G.; Scorrano, F. Current trends in Smart City initiatives: Some stylised facts. Cities 2014, 38, 25-36. [CrossRef]

8. Washburn, D.; Sindhu, U.; Balaouras, S.; Dines, R.A.; Hayes, N.; Nelson, L.E. Helping CIOs understand "smart city" initiatives. Growth 2009, 17, 1-17.

9. Dirks, S.; Keeling, M.; Dencik, J. How Smart Is Your City? IBM Institute for Business Value: Somers, NY, USA, 2009.

10. Nam, T.; Pardo, T.A. Conceptualizing smart city with dimensions of technology, people, and institutions. In Proceedings of the 12th Annual International Digital Government Research Conference on Digital Government Innovation in Challenging Times, College Park, MD, USA, 12-15 June 2011; ACM Press: New York, NY, USA, 2011; pp. 282-291.

11. Kitchin, R.; Lauriault, T.P.; McArdle, G. Knowing and governing cities through urban indicators, city benchmarking and real-time dashboards. Reg. Stud. Reg. Sci. 2015, 2, 6-28. [CrossRef]

12. Jing, C.; Du, M.; Li, S.; Liu, S. Geospatial Dashboards for Monitoring Smart City Performance. Sustainability 2019, 11, 5648. [CrossRef]

13. Colding, J.; Barthel, S.; Sörqvist, P. Wicked Problems of Smart Cities. Smart Cities 2019, 2, 512-521. [CrossRef]

14. Few, S. Dashboard Design: Displaying Data for At-a-Glance Monitoring, 2nd ed.; Analytics Press: Burlingame, CA, USA, 2013.

15. Mattern, S. Urban Dashboards. In Understanding Spatial Media; Kitchin, R., Lauriault, T.P., Wilson M.W., Eds.; SAGE Publications: London, UK, 2017; pp. 74-83.

16. O'Brien, O. BikeSharp London. Available online: https://bikesharemap.com/london/timeline (accessed on 5 October 2019).

17. Che Soh, Z.H.; Shafie, M.S.; Shafie, M.A.; Noraini Sulaiman, S.; Ibrahim, M.N.; Afzal Che Abdullah, S. IoT Water Consumption Monitoring \& Alert System. In Proceedings of the 2018 International Conference on Electrical Engineering and Informatics (ICELTICs), Banda Aceh, Indonesia, 19-20 September 2018; pp. 168-172.

18. Western Pennsylvania Regional Data Center Lots and Metered Parking. Available online: https://tools. wprdc.org/parking/ (accessed on 6 October 2019).

19. Gray, S.; O’Brien, O.; Hügel, S. Collecting and Visualizing Real-Time Urban Data through City Dashboards. Built Environ. 2016, 42, 498-509. [CrossRef]

20. Lock, O.; Bednarz, T.; Leao, S.Z.; Pettit, C. A review and reframing of participatory urban dashboards. City Cult. Soc. 2020, 20, 100294. [CrossRef] 
21. Thomas, J.J.; Cook, K.A. A visual analytics agenda. IEEE Comput. Graph. Appl. 2006, 26, 10-13. [CrossRef]

22. Andrienko, G.; Andrienko, N.; Jankowski, P.; Keim, D.; Kraak, M.-J.; MacEachren, A.; Wrobel, S. Geovisual analytics for spatial decision support: Setting the research agenda. Int. J. Geogr. Inf. Sci. 2007, 21, 839-857. [CrossRef]

23. Kraak, M.-J. From Geovisualisation Toward Geovisual Analytics. Cartogr. J. 2008, 45, 163-164.

24. Rey, S.J.; Mack, E.A.; Koschinsky, J. Exploratory Space-Time Analysis of Burglary Patterns. J. Quant. Criminol. 2012, 28, 509-531. [CrossRef]

25. Santos, R.B. Crime Analysis with Crime Mapping; SAGE Publications: Thousand Oaks, CA, USA, 2013.

26. Andrienko, G.; Andrienko, N.; Dykes, J.; Kraak, M.-J.; Schumann, H. GeoVisual analytics, time to focus on time. Inf. Vis. 2014, 13, 187-189. [CrossRef]

27. London Metropolitan Police Crime Data Dashboard. Available online: https://www.met.police.uk/sd/ stats-and-data/met/crime-data-dashboard/ (accessed on 7 October 2019).

28. Seattle Police Department Crime Dashboard. Available online: https://www.seattle.gov/police/ information-and-data/crime-dashboard (accessed on 7 October 2019).

29. Toronto Police Service Data Analytics. Available online: http://data.torontopolice.on.ca/pages/dataanalytics (accessed on 7 October 2019).

30. Toronto Police Service Toronto Police Maps. Available online: http://data.torontopolice.on.ca/pages/maps (accessed on 7 October 2019).

31. Secretaria de Estado da Segurança Pública e da Paz Social Painel de Monitoramento e Consulta das Estatísticas Criminais do Distrito Federal. Available online: https://imagem-govfed.maps.arcgis.com/ apps / opsdashboard/index.html\#/23ebbd91a0f84380ac32f58e08f5bafb (accessed on 7 October 2019).

32. Vancouver Police Department GeoDASH Crime Statistics Hub. Available online: https:/ /vancouverpolice. maps.arcgis.com/apps/opsdashboard/index.html\#/645556b3fd85407eaa3193a18ed4093a (accessed on 7 October 2019).

33. Douglas County Government Crime Data Dashboard-Douglas County, Colorado. Available online: https: / / www.arcgis.com/apps/opsdashboard/index.html\#/9b16e9397a4645d0858444ffc3cafb48 (accessed on 7 October 2019).

34. Halifax Regional Police Criminal Incidents in Halifax. Available online: https:/ /www.arcgis.com/apps / opsdashboard/index.html\#/b8c9031ff4f2496ab23a44e6ee1f6937 (accessed on 7 October 2019).

35. Belize Crime Observatory Data Hub. Available online: https://hub--belizeco.opendata.arcgis.com/ (accessed on 7 October 2019).

36. Chen, X.; Pranowo, L. Pittsburgh Crime Map 2017. Available online: https://visiuchen.shinyapps.io/ PITTSBURGH-CRIME-MAP / (accessed on 6 October 2019).

37. Batty, M. A perspective on city dashboards. Reg. Stud. Reg. Sci. 2015, 2, 29-32. [CrossRef]

38. Patronato de la Feria Nacional de San Marcos-Coordinación Estatal de Planeación y Proyectos Datos de Afluencia. Available online: http:/ /www.aguascalientes.gob.mx/ceplap/datos/default.aspx (accessed on 23 April 2019).

39. México Desconocido Historia de la Feria de San Marcos en Aguascalientes. Available online: https://www. mexicodesconocido.com.mx/feria-san-marcos-aguascalientes.html (accessed on 13 February 2019).

40. Diario Oficial de la Federación (DOF). Secretaría de Gobernación Norma Técnica para la Clasificación Nacional de Delitos del Fuero Común para Fines Estadísticos. 2011. Available online: http:/ / dof.gob.mx/ nota_detalle.php?codigo=5226002\&fecha=21/12/2011 (accessed on 12 December 2016).

41. Diario Oficial de la Federación (DOF). Secretaría de Gobernación Norma Técnica para la Clasificación Nacional de Delitos del Fuero Común para Fines Estadísticos. 2018. Available online: https:/ /www.dof.gob. $\mathrm{mx} /$ nota_detalle.php?codigo=5541706\&fecha=22/10/2018 (accessed on 11 October 2019).

42. Secretariado Ejecutivo del Sistema Nacional de Seguridad Pública (SESNSP) Incidencia Delictiva. Available online: https://www.gob.mx/sesnsp/acciones-y-programas/incidencia-delictiva-87005 (accessed on 24 February 2020).

43. Secretariado Ejecutivo del Sistema Nacional de Seguridad Pública (SESNSP) Incidencia delictiva del Fuero Común, metodología anterior. Available online: https://www.gob.mx/sesnsp/acciones-y-programas / incidencia-delictiva-del-fuero-comun (accessed on 11 October 2019). 
44. Secretariado Ejecutivo del Sistema Nacional de Seguridad Pública (SESNSP) Incidencia delictiva del Fuero Común, nueva metodología. Available online: https://www.gob.mx/sesnsp/acciones-y-programas / incidencia-delictiva-del-fuero-comun-nueva-metodologia (accessed on 11 October 2019).

45. Instituto Nacional de Geografía y Estadística (INEGI) Espacio y datos de México. Available online: https: / /www.inegi.org.mx/app/mapa/espacioydatos/ (accessed on 15 April 2016).

46. Hägerstrand, T. Diorama, path and project. J. Econ. Soc. Geogr. 1982, 73, 323-339. [CrossRef]

47. Hägerstrand, T. Innovation Diffusion as a Spatial Process; University of Chicago Press: Chicago, IL, USA, 1967.

48. Koussoulakou, A.; Kraak, M.J. Spatia-temporal maps and cartographic communication. Cartogr. J. 1992, 29, 101-108. [CrossRef]

49. Shepherd, I.D.H. Putting time on the map: Dynamic displays in data visualisation and GIS. In Innovations in GIS 2; Fisher, P., Ed.; Taylor \& Francis: Bristol, PA, USA, 1995; pp. 169-187.

50. Wood, J.; Slingsby, A.; Dykes, J. Visualizing the dynamics of London's bicycle hire scheme. Cartogr. Int. J. Geogr. Inf. Geovis. 2011, 46, 239-251. [CrossRef]

51. Buchmüller, J.; Janetzko, H.; Andrienko, G.; Andrienko, N.; Fuchs, G.; Keim, D.A. Visual Analytics for Exploring Local Impact of Air Traffic. Comput. Graph. Forum 2015, 34, 181-190. [CrossRef]

52. von Landesberger, T.; Brodkorb, F.; Roskosch, P.; Andrienko, N.; Andrienko, G.; Kerren, A. MobilityGraphs: Visual Analysis of Mass Mobility Dynamics via Spatio-Temporal Graphs and Clustering. IEEE Trans. Vis. Comput. Graph. 2016, 22, 11-20. [CrossRef]

53. Brunsdon, C.; Corcoran, J.; Higgs, G. Visualising space and time in crime patterns: A comparison of methods. Comput. Environ. Urban Syst. 2007, 31, 52-75. [CrossRef]

54. Townsley, M. Visualising space time patterns in crime: The hotspot plot. Crime Patterns Anal. 2008, 1, 61-74.

55. Roth, R.; Ross, K.; MacEachren, A. User-Centered Design for Interactive Maps: A Case Study in Crime Analysis. ISPRS Int. J. Geo-Inf. 2015, 4, 262-301. [CrossRef]

56. Wang, K.; Zhou, X.; Li, L. Disentangle crime hot spots and displacements in space and time. In Proceedings of the 1st ACM SIGSPATIAL Workshop on Geospatial Humanities-GeoHumanities'17, Los Angeles Area, CA, USA, 7-10 November 2017; ACM Press: New York, NY, USA, 2017; pp. 55-59.

57. Nakaya, T.; Yano, K. Visualising Crime Clusters in a Space-time Cube: An Exploratory Data-analysis Approach Using Space-time Kernel Density Estimation and Scan Statistics. Trans. GIS 2010, 14, $223-239$. [CrossRef]

58. Helbich, M.; Jokar Arsanjani, J. Spatial eigenvector filtering for spatiotemporal crime mapping and spatial crime analysis. Cartogr. Geogr. Inf. Sci. 2015, 42, 134-148. [CrossRef]

59. Contreras, C.; Hipp, J.R. Drugs, Crime, Space, and Time: A Spatiotemporal Examination of Drug Activity and Crime Rates. Justice Q. 2019, 1-23. [CrossRef]

60. Gong, J.; Li, S.; Wan, B. A Regional Approach to Assessing and Visualizing Spatiotemporal Clustering of Crime Events. Pap. Appl. Geogr. 2019, 5, 26-44. [CrossRef]

61. Payne, B.K.; Oliver, W.M.; Marion, N.E. Introduction to Criminal Justice; SAGE Publications: Thousand Oaks, CA, USA, 2016.

62. Murray, A.T.; Kim, K.; Davis, J.W.; Machiraju, R.; Parent, R. Coverage optimization to support security monitoring. Comput. Environ. Urban Syst. 2007, 31, 133-147. [CrossRef]

63. Murray, A.T. Maximal Coverage Location Problem: Impacts, Significance, and Evolution. Int. Reg. Sci. Rev. 2016, 39, 5-27. [CrossRef]

64. Real, R.; Vargas, J.M. The Probabilistic Basis of Jaccard's Index of Similarity. Syst. Biol. 1996, 45, 380-385. [CrossRef]

65. Weisburd, D. The Law of Crime Concentration and the Criminology of Place. Criminology 2015, 53, $133-157$. [CrossRef]

66. Chainey, S.P.; Monteiro, J. The dispersion of crime concentration during a period of crime increase. Secur. J. 2019, 32, 324-341. [CrossRef]

67. Braga, A.A.; Andresen, M.A.; Lawton, B. The Law of Crime Concentration at Places: Editors' Introduction. J. Quant. Criminol. 2017, 33, 421-426. [CrossRef]

68. Ratcliffe, J. Video Surveillance of Public Places; U.S. Department of Justice: Washington, DC, USA, 2006.

69. Piza, E.L.; Welsh, B.C.; Farrington, D.P.; Thomas, A.L. CCTV surveillance for crime prevention. Criminol. Public Policy 2019, 18, 135-159. [CrossRef] 
70. Ashby, M.P.J. The Value of CCTV Surveillance Cameras as an Investigative Tool: An Empirical Analysis. Eur. J. Crim. Policy Res. 2017, 23, 441-459. [CrossRef]

71. Altahir, A.A.; Asirvadam, V.S.; Hamid, N.H.; Sebastian, P.; Saad, N.; Ibrahim, R.; Dass, S.C. Modeling Multicamera Coverage for Placement Optimization. IEEE Sens. Lett. 2017, 1, 1-4. [CrossRef]

(C) 2020 by the author. Licensee MDPI, Basel, Switzerland. This article is an open access article distributed under the terms and conditions of the Creative Commons Attribution (CC BY) license (http:/ / creativecommons.org/licenses/by/4.0/). 